\title{
Evaluation of Lead Exposures at a Bullet Manufacturer
}

Report 2017-0146-3310

April 2018 


\section{Authors: David A. Jackson, MD}

\section{Gregory A. Burr, ClH}

Analytical Support: Jennifer Roberts, Maxxam Analytics

Desktop Publisher: Jennifer Tyrawski

Editor: Ellen Galloway

Medical Field Assistance: Marie de Perio, Deborah Sammons; Carol R. Braun, Lori J. Harris-

Franklin, Missouri Department of Health and Senior Services

Keywords: North American Industry Classification System (NAICS) 332994 (Small Arms, Ordnance, and Ordnance Accessories Manufacturing), Missouri, Lead, Ventilation, Blood Lead Level, Housekeeping, Respirators, Noise, Bullet

\section{Disclaimer}

The Health Hazard Evaluation Program investigates possible health hazards in the workplace under the authority of the Occupational Safety and Health Act of 1970 (29 U.S.C. S 669(a)(6)). The Health Hazard Evaluation Program also provides, upon request, technical assistance to federal, state, and local agencies to investigate occupational health hazards and to prevent occupational disease or injury. Regulations guiding the Program can be found in Title 42, Code of Federal Regulations, Part 85; Requests for Health Hazard Evaluations (42 CFR Part 85).

\section{Availability of Report}

Copies of this report have been sent to the employer, employees, and union at the plant. The state and local health department and the Occupational Safety and Health Administration Regional Office have also received a copy. This report is not copyrighted and may be freely reproduced.

\section{Recommended Citation}

NIOSH [2018]. Evaluation of lead exposures at a bullet manufacturer. By Jackson DA and Burr GA. Cincinnati, OH: U.S. Department of Health and Human Services, Centers for Disease Control and Prevention, National Institute for Occupational Safety and Health, Health Hazard Evaluation Report 2017-0146-3310, https:/ /www.cdc.gov/niosh/hhe/reports/pdfs/2017-0146-3310.pdf. 


\section{Table of Contents}

\section{Report}

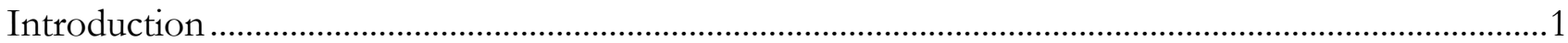

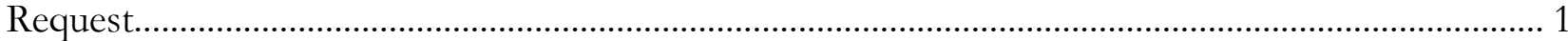

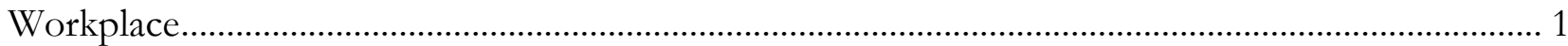

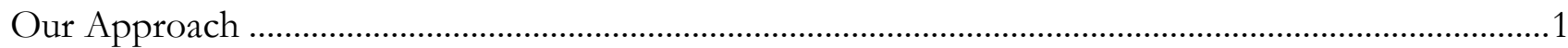

Our Key Findings...................................................................................................................

Employees had high blood lead levels ........................................................................................ 1

Work practices and conditions contributed to lead exposures .......................................................... 2

Employees' airborne metal exposures were below current occupational exposure limits .................. 3

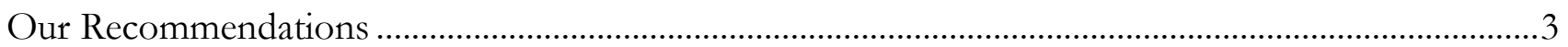

\section{Supporting Technical Information}

Section A: Workplace Information................................................................................................. A-1

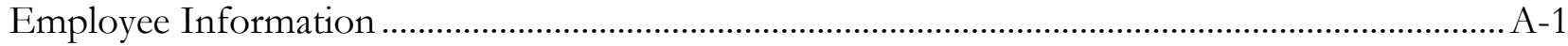

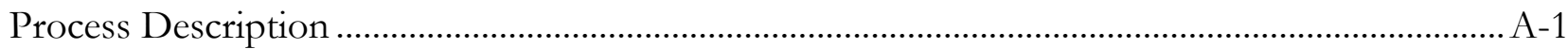

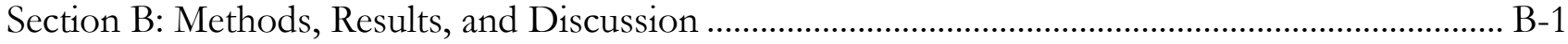

Methods: Health and Safety Program and Document Review........................................................ B-1

Results: Health and Safety Program and Document Review............................................................. B-1

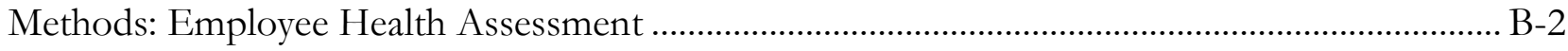

Results: Employee Health Assessment …………………………………………………... B-2

Methods: Observations of Work Processes, Practices, and Conditions ……………………….... B-4

Results: Observations of Work Processes, Practices, and Conditions ............................................. B-4

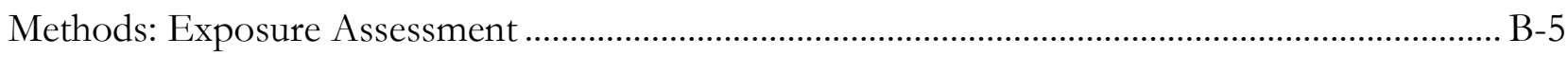

Results: Exposure Assessment ........................................................................................ B-7

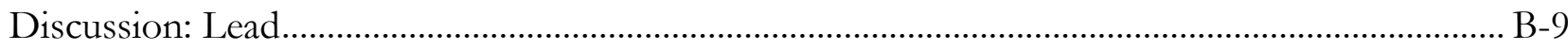

Discussion: Other....................................................................................................... B-10

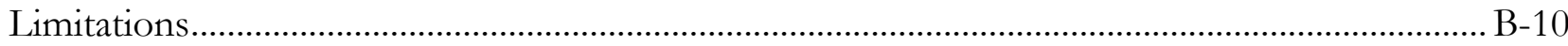

Section C: Tables ............................................................................................................. C-1

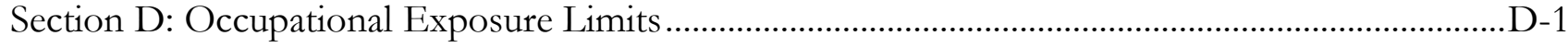

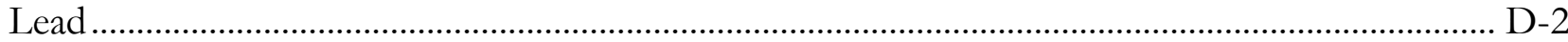

Noise

Section E: References ……………………………………………………………………... E-1 
This page left intentionally blank 


\section{Introduction}

\section{Request}

The owner at a lead bullet manufacturer was concerned about employees' lead exposure.

\section{Workplace}

Making bullets involved the following steps:

- Melting an alloy that contains lead, antimony, and tin, and then casting the bullets.

- Sizing and lubricating the cast bullets, a process called lubrisizing. In some instances, the cast bullets were coated instead of being lubrisized.

- Packaging and shipping the bullets.

At the time of our visit, 11 individuals (including the owner) worked at the company. The company had one 8-hour work shift per day, Monday through Friday.

To learn more about the workplace, go to Section A in the Supporting Technical Information

\section{Our Approach}

We visited the company on October 23-24, 2017. On this visit we:

- Observed work processes, work practices, and ventilation

- Measured employee exposures to lead, antimony, and tin in air and on surfaces, and noise

- Interviewed employees about their work and their health

- Measured employees' blood lead levels

To learn more about our methods, go to Section B in the Supporting Technical Information

\section{Our Key Findings}

\section{Employees had high blood lead levels}

- Nine of 10 employees, including those working in the packaging and shipping bay, had blood lead levels that were equal to or above 5 micrograms per deciliter, a level that the National Institute for Occupational Safety and Health considers high. The range was 4-35 micrograms per deciliter.

- The three employees with the highest blood lead levels worked in the casting bay and coating room.

- None of the tested employees had blood lead levels that were above the Occupational Safety and Health Administration (OSHA) limit to be removed from work of 60 micrograms per 
deciliter on a single test. However, this limit was set years ago and has not yet been updated to reflect current scientific knowledge.

\section{Work practices and conditions contributed to lead exposures}

- The company did not have a written lead monitoring or control program.

o We saw employees who did not consistently wear gloves when handling bullets or potentially contaminated equipment. Four employees also reported inconsistent glove use in our interviews (see Figure 1).

o We saw employees eating, drinking, or smoking without first washing hands with lead removal soap.

o We saw food and drink in bullet production areas (see Figure 2).

o We saw employees dry sweeping the floor and using a dry cloth to wipe potentially leadcontaminated surfaces. These practices can increase the chance for lead dust to get into the air.

o Employees did not have dedicated work clothes or shoes. The building also did not have lockers to separate work and street clothes or an on-site laundry for washing lead contaminated work clothes. This increases the risk of take-home lead exposure and cross-contamination in the building.

- We found lead on employees' hands after they washed up at lunch and before they went home for the day. We found smaller amounts of antimony and tin on their hands.

- We found lead and smaller amounts of antimony and tin on surfaces in non-production areas such as the employee break room, the office, and an outdoor picnic table employees used.

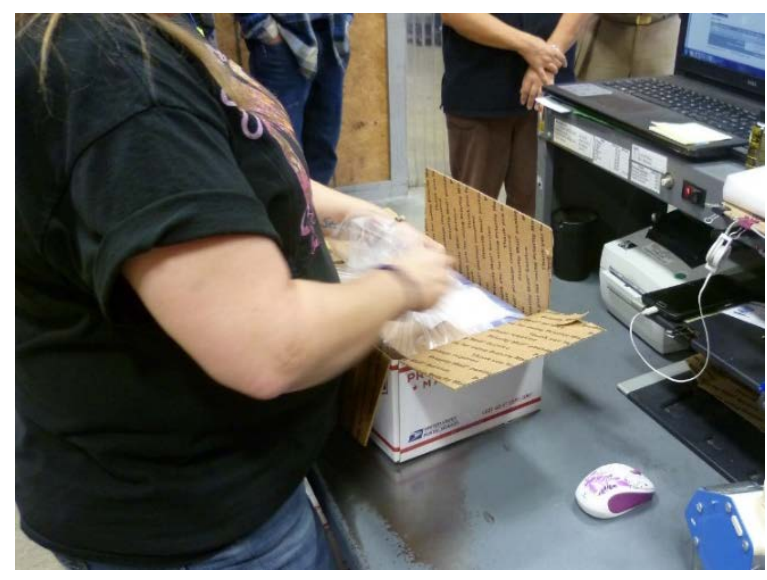

Figure 1. Packaging boxes of bullets without gloves.

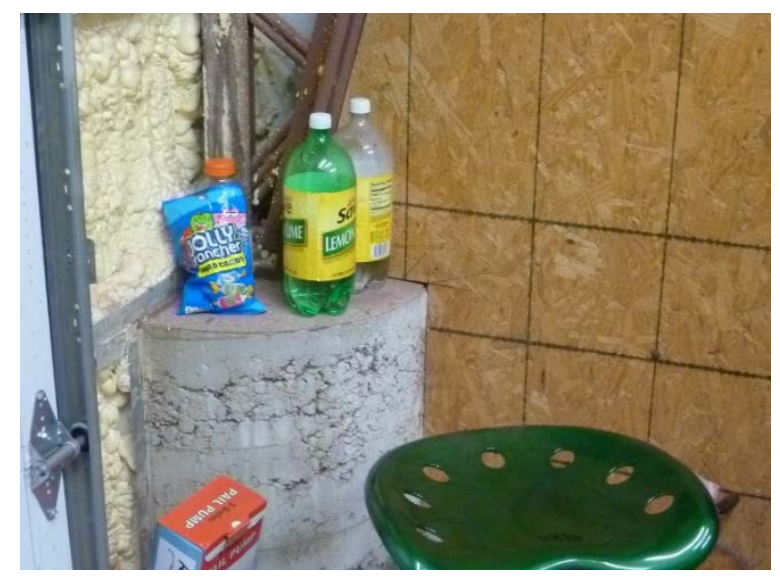

Figure 2. Three soft drink bottles and a package of candy stored in the bullet coating room. 


\section{Employees' airborne metal exposures were below current occupational exposure limits}

- Employees' full-shift personal air exposures to lead ranged from 2.3 to 20 micrograms per cubic meter of air. These exposures are below the current OSHA permissible exposure limit and the National Institute for Occupational Safety and Health recommended exposure limit for lead of 50 micrograms per cubic meter of air. However, both of these occupational exposure limits for lead were set years ago and have not yet been updated to reflect current scientific knowledge.

- Employee full-shift personal air exposures to antimony and tin were even lower than those for lead, and were well below applicable occupational exposure limits.

- The coating room employee was exposed to metals in the powdered paint, including aluminum, titanium, and cobalt. These exposures were below applicable occupational exposure limits.

To learn more about our methods, go to Section B in the Supporting Technical Information

\section{Our Recommendations}

Benefits of Improving Workplace Health and Safety:

个 Improved worker health and well-being $\uparrow$ Improved image and reputation

$\uparrow$ Better workplace morale

个 Better products, processes, and services

$\uparrow$ Better employee recruiting and retention

$\uparrow$ Could increase overall cost savings

The recommendations below are based on the findings of our evaluation. For each recommendation, we list a series of actions you can take to address the issue at your workplace. The actions at the beginning of each list are preferable to the ones listed later. The list order is based on a well-accepted approach called the "hierarchy of controls." The hierarchy of controls groups actions by their likely effectiveness in reducing or removing hazards. In most cases, the preferred approach is to eliminate hazardous materials or processes and install engineering controls to reduce exposure or shield employees. Until such controls are in place, or if they are not effective or feasible, administrative measures and personal protective equipment may be needed. Read more about the hierarchy of controls here: https://www.cdc.gov/niosh/topics/hierarchy/.

We encourage the company to use a health and safety committee to discuss our recommendations and develop an action plan. Both employee representatives and management representatives should be included on the committee. Helpful guidance can be found in "Recommended Practices for Safety and Health Programs" Web link: https://www.osha.gov/shpguidelines/index.html. 


\section{Recommendation 1: Improve work practices, conditions, and training to reduce employees' contact with lead}

Why? Lead is considered toxic to all organ systems and serves no useful purpose in the body. Overexposure or unnecessary exposure can contribute to long-term lead poisoning. Employees exposed to lead may not have symptoms, or they may have nonspecific symptoms such as headache, joint and muscle aches, weakness, and fatigue. These can worsen over time and could be associated with the following:

- more sick leave

- job loss

- lower quality of life

We found that nine of 10 employees had high blood lead levels. Although personal airborne lead exposures were below occupational exposure limits, we found lead on employees' hands after washing and on non-work surfaces such as in the breakroom and on an outdoor picnic table. Inconsistent handwashing, dry sweeping that generates airborne lead dust, and eating and drinking in lead contaminated areas contributed to unnecessary lead exposures through inhalation and ingestion.

\section{How? At your workplace, we recommend these specific actions:}

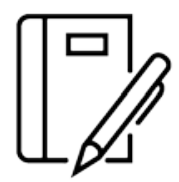

\section{Start a lead program that includes:}

- Following guidance from the OSHA lead standard, 29 CFR 1910.1025; https://www.osha.gov/pls/oshaweb/owadisp.show document?p table $=$ STANDARDS\&p id $=10030$.

- Providing medical surveillance as outlined in Table D2 of this report and following all requirements of the OSHA lead standard.

- Educating employees on lead hazards. More information is available at https://www.osha.gov/pls/oshaweb/owadisp.show document?p table=STANDA

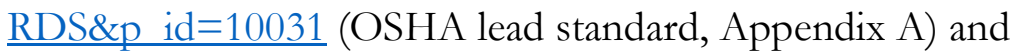
https://www.osha.gov/pls/oshaweb/owadisp.show document?p table=STANDA

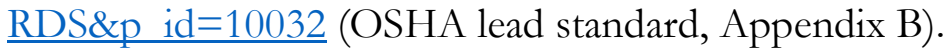

- Displaying the OSHA Quick Card on Take-home Lead Prevention in a highly visible location (available at https://www.osha.gov/Publications/OSHA3680.pdf), or providing copies of this card to all employees.

- Providing annual lead refresher training for employees.

- Starting a hazard communication program according to the OSHA hazard communication standard, 29 CFR 1910.1200: https://www.osha.gov/Publications/OSHA3695.pdf. 


\section{Require all employees to always wash their hands before eating, drinking, or smoking, and each time they leave the workplace.}

- Educate employees about the need to use lead removal soap before using abrasive hand cleaner (see Figure 3).

- Make sure employees are aware that abrasive cleaners can remove the outer layer of skin and could increase lead absorption.

- Replace the high speed air hand dryer in the employee bathroom with disposable towels (e.g., paper towels)

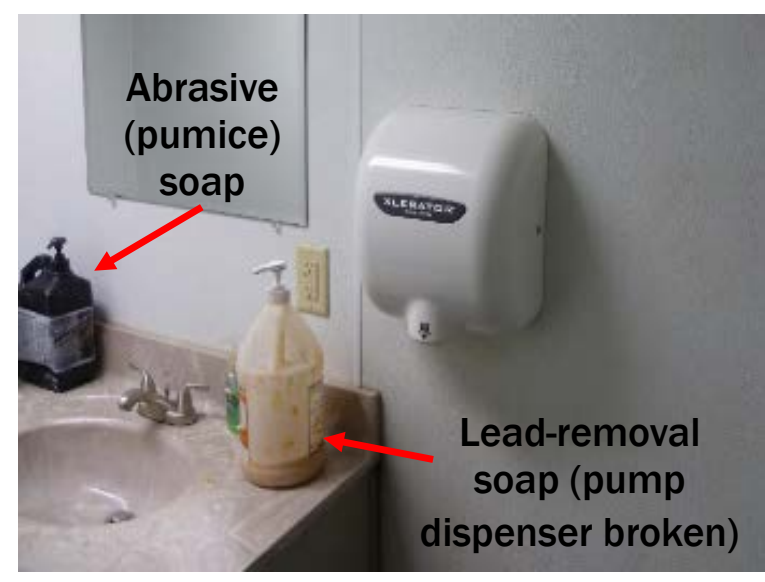

Figure 3. Employee restroom. to reduce the risk for creating airborne lead dust during hand drying.

- Encourage employees to stop smoking.

\section{Do not allow employees to consume or store food or drink in bullet production areas.}

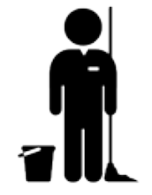

\section{Use wet cleaning methods to clean potentially contaminated surfaces.}

- Use wet cleaning methods with a lead removal solution, or use a vacuum equipped with a high efficiency particulate air filter.

- Stop using brooms and dry sweeping, even with dust suppression compounds.

- Clean the employee breakroom and outdoor picnic table more often.

- Remind employees about these proper cleaning methods.

\section{Require everyone entering the bullet production areas to wear no-slip, disposable shoe covers.}

- Maintain a supply of shoe covers at the entrance to the bullet production areas so that employees can put on shoe covers just after entering these areas.

- Provide a shoe cover disposal bin on the bullet production side of exit doors.

- Make sure that all shoe cover disposal bins have lids that close.

- As an alternative to disposable shoe covers, provide employees with dedicated work shoes that meet American National Standards Institute performance requirements. 
Use sticky mats at exit doors from the bullet production area to the employee breakroom, bathroom, and office to help prevent employees from tracking lead on their shoes to nonproduction areas.

Provide employees with an on-site laundry, dedicated work clothes, and separate lockers for street clothes and work clothes.

- This will reduce the risk of take-home lead and cross-contamination in the building.

- Instead of an on-site laundry, you could contract with an off-site laundry service that is qualified to handle lead-contaminated garments such as employee uniforms.

Encourage employees to talk to their healthcare provider about their exposure to lead and about the possibility of take-home contamination with lead.

- Encourage employees to have people who live with them or regularly ride in their vehicles to get their blood lead levels tested.

Require employees to wear disposable non-latex (e.g., nitrile or vinyl) gloves at all times when working in bullet production areas.

Require employees to wear safety glasses at all times when working in bullet production areas.

Recommendation 2: Improve ventilation in the bullet casting bay to reduce airborne lead levels

Why? Lead dust and lead fume can be inhaled. Although employees' airborne lead exposures did not exceed occupational exposure limits, improving the local exhaust ventilation will further reduce airborne levels and lead exposure to employees in the casting bay. We found that the local exhaust ventilation system did not effectively capture smoke when the bullet casters were fluxed.

How? At your workplace, we recommend these specific actions:

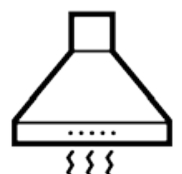

III

Improve the local exhaust ventilation at the bullet casters.

- One way to improve the ventilation is to move the overhead exhaust hoods closer to the bullet casters. A disadvantage of this option may be the cost of lowering the 
exhaust vents. Lowering the hoods may also reduce the working space when employees have to access the bullet casters (see Figure 4).

- Another way to improve the ventilation is by attaching flexible, transparent strip curtains to the exhaust hoods. These curtains would hang down and surround the bullet casters. Advantages compared to the previous option may be lower installation costs and less reduction in the working space when employees access the bullet casters.

- Minimize floor and pedestal fans in the bullet casting bay because they can disrupt the effectiveness of the local exhaust ventilation system. However, these fans would be less disruptive to the exhaust ventilation if strip curtains are installed around the bullet casters.

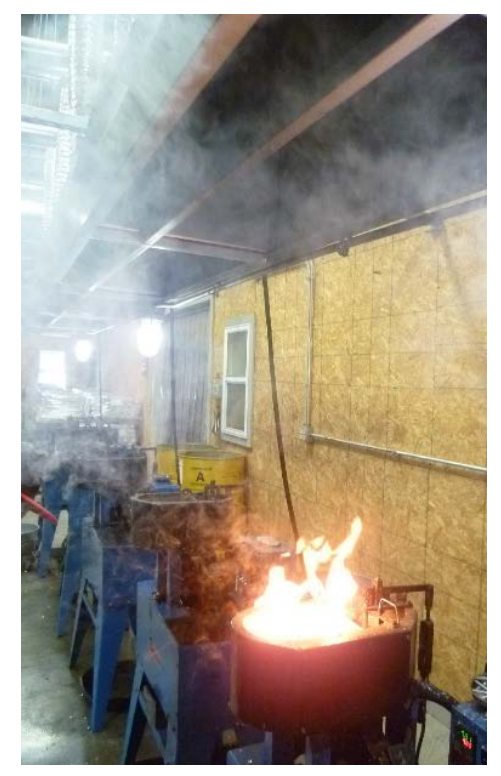

Figure 4. Flux smoke not captured by the overhead local exhaust ventilation.

\section{Ensure employees and contractors changing air filters in the casting bay comply with the OSHA lead standard.}

\section{Recommendation 3: Address other health and safety issues we found during our evaluation.}

Why? A workplace can have multiple health hazards that cause worker illness or injury. Similar to the ones identified above, these hazards can potentially cause serious health symptoms and lower morale and quality of life for your employees, and increase costs to your business. We found the following additional issues at your workplace:

- Skin burns among casting bay employees (see Figure 5).

- Risk of foot injury and lack of safety shoe use among employees.

- Potential noise overexposures and improper hearing protection (see Figure 6).

- Required respirator use by the coating room employee in the absence of a written respiratory protection program (see Figure 7).

- An employee mixed powdered paint with a solvent on an unventilated work bench (see Figure 8). When heated, the powdered paint released acetone and other volatile organic compounds, including isopropyl alcohol and 2-hydroxybenzaldehyde. The latter compound was likely responsible for the odor when coated bullets were heated.

Although these issues were not the main focus of our evaluation, they could harm your employees' health and safety and should be addressed. 
How? At your workplace, we recommend these specific actions:

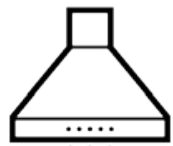

\\}?
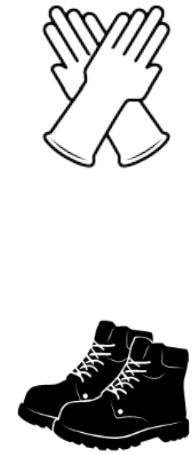

Ensure that employees wear safety shoes that meet American National Standards Institute minimum compression and impact performance standards or provide equivalent protection.

- More guidance is available at https://www.osha.gov/Publications/osha3151.pdf.
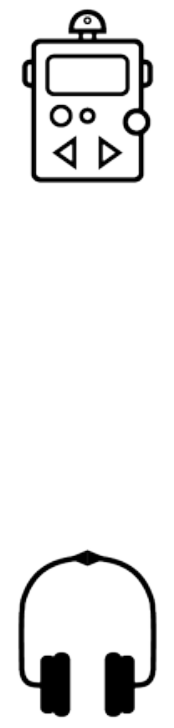

Ensure that employees who are overexposed to noise are provided with appropriate hearing protection and that they wear this hearing protection properly.

- Ear buds and head phones are not considered hearing protection.

Decide if employees need to wear respirators when they are working.

- If respirators are required, you will need a written respiratory protection program consistent with the OSHA respiratory protection standard: https://www.osha.gov/Publications/3384small-entity-for-respiratory-protectionstandard-rev.pdf. 
- If respirators are voluntary, a written program is not needed but employees must be provided with Appendix D of the OSHA respiratory protection standard:

https://www.osha.gov/pls/oshaweb/owadisp.show document?p table=STANDA RDS\&p id=9784.

- Ensure that employees do not have facial hair that can interfere with the sealing surface of tight-fitting respirators.

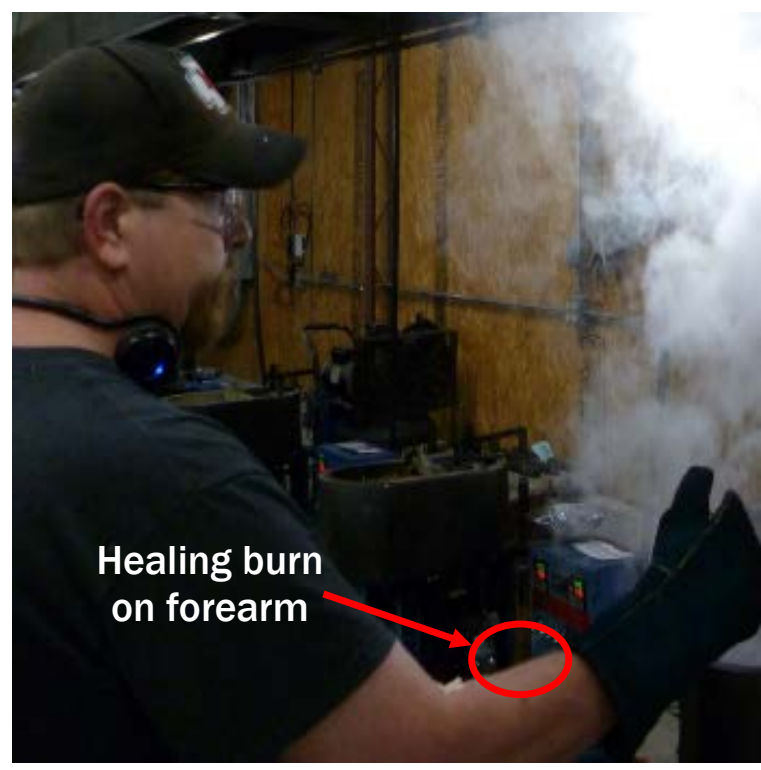

Figure 5. Employee with healing burn on forearm fluxing a bullet caster.

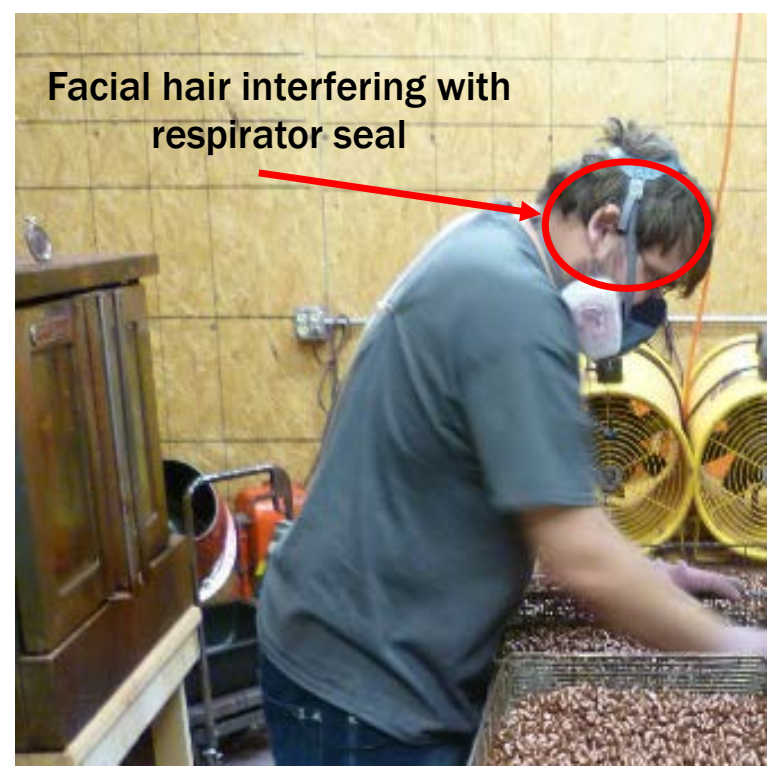

Figure 7. Employee with facial hair wearing a half-mask tight-fitting air-purifying respirator. The company did not have a written respiratory protection program.

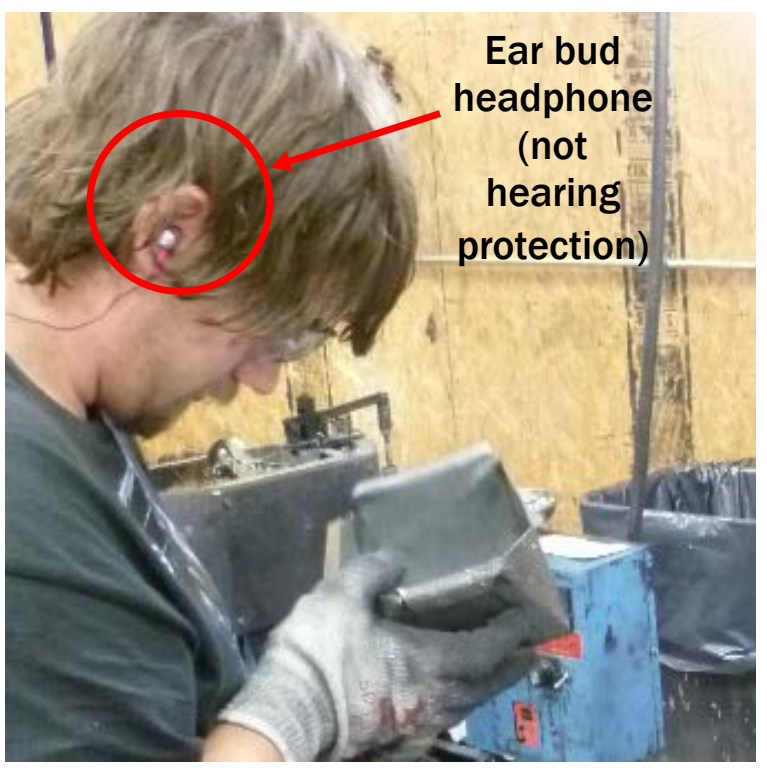

Figure 6. Employee in high noise area wearing audio ear buds. The company did not have a hearing conservation program.

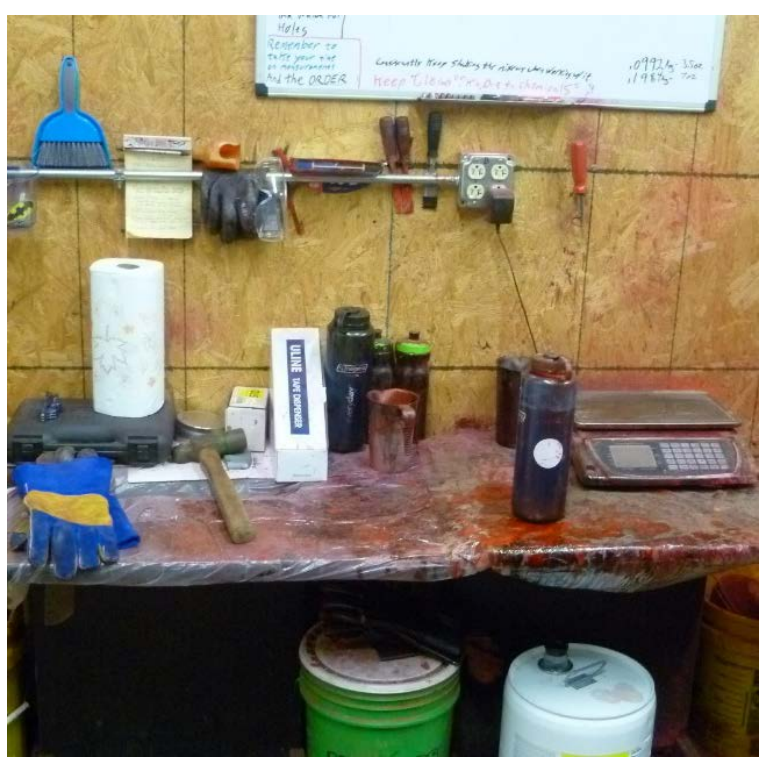

Figure 8. Unventilated work bench in bullet coating room where employee mixed powdered paint and solvent. 
This page left intentionally blank 


\section{Evaluation of Lead Exposures at a Bullet Manufacturer}

Supporting Technical Information

Report 2017-0146-3310

April 2018 


\section{Section A: Workplace Information}

\section{Building}

- The company was in a single story rectangular metal frame building.

- Production was divided among three nearly equal-sized bays. The bays included casting (west side of the building), lubrisizing (middle of the building), and packaging and shipping (east side of the building). The offices of the owner and office manager/vice president were adjacent to the shipping bay.

- The casting bay and packaging and shipping bay each had roll-up overhead doors. Employees used these doors to transfer raw materials and finished production into and out of the building.

- The bullet coating room was separate from the three production bays and had its own exterior entrance and ventilation system. One employee worked in the coating room.

\section{Employee Information}

- Ten employees and one owner worked at the company at time of evaluation. The employees were not unionized.

- The work shift was 8-hours per day, Monday through Friday.

- The median age of employees was 39 years (range: 25-65 years).

- The median job tenure was 3.5 years (range: 2 weeks-10 years).

\section{Process Description}

\section{Step 1: Casting}

- The company received 8-pound lead ingots on pallets. Employees used a forklift to move these pallets into the casting bay. The lead ingots were notched to allow employees to break them by hand into pieces small enough to fit into the bullet caster melting pot.

- At the time of our visit, the company had a supply of lead "pigs" (60-pound lead ingots). Because of their larger size, the lead pigs had to be manually cut to sizes small enough to fit into the bullet caster melting pot. One employee used a hand-held, gasoline-powered, water-cooled cut-off saw to cut the lead pigs outside the building. No cutting was done during our evaluation. The owner estimated it could take years to use up the supply of lead pigs (see Figures 9 and 10).

- Lead was melted in electrically-heated casters to form bullets. At the time of the evaluation, 8 of the 14 bullet casters were operating, a typical production rate according to the owner of the company. The casters heated the lead to between $750^{\circ} \mathrm{F}$ and $850^{\circ} \mathrm{F}$. 


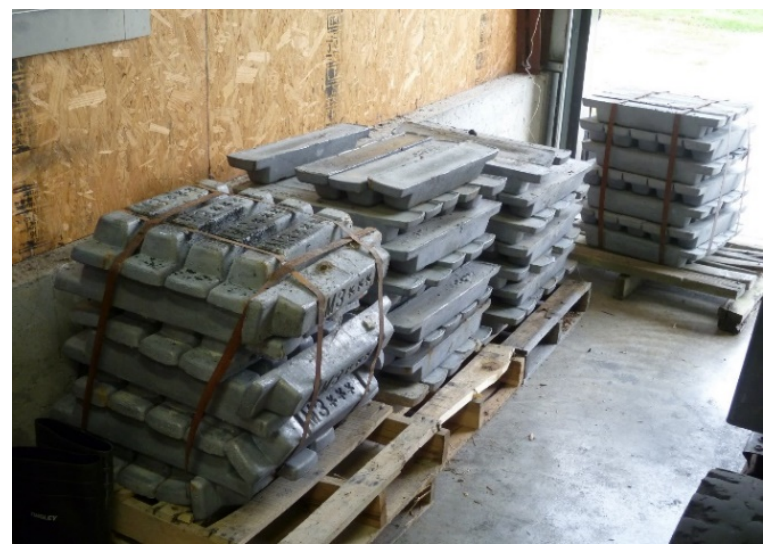

Figure 9. Four pallets of lead ingots (called pigs) stored in the casting bay. Each lead pig weighed about 60 pounds.

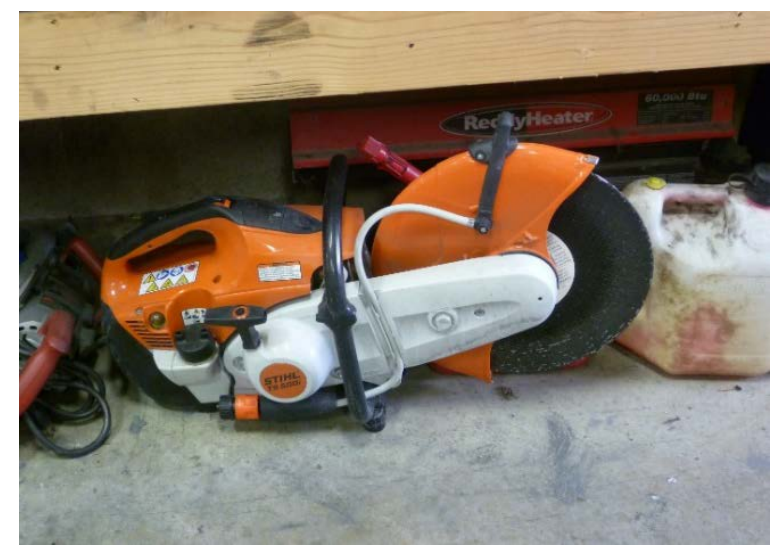

Figure 10. Hand-held, gasoline-powered, watercooled abrasive cutoff saw. An employee used the saw to cut the 60 pound lead ingots into sizes small enough to fit in the bullet caster melting pot.

\section{Step 2: Bullet Sizing, Wax Lubricating, and Coating}

- Employees manually moved containers of the cast bullets to the lubrisizing bay for hydraulic sizing to the desired gauge. The sized bullets were then lubricated with a wax-based material or manually transferred to the coating room.

- Some bullets received a proprietary coating. Benefits of the coating included eliminating the need for the end user to touch bare lead during reloading and increasing the bullet's lubricity. The coating room employee mixed a dry coating powder in a solvent and then poured this mixture onto uncoated bullets in a tumbler. The bullets were then baked in an oven. Baking removed any residual solvent and hardened the coating to the bullet. The coating room employee carried the coated bullets back to packaging and shipping (see Figures 11 and 12).

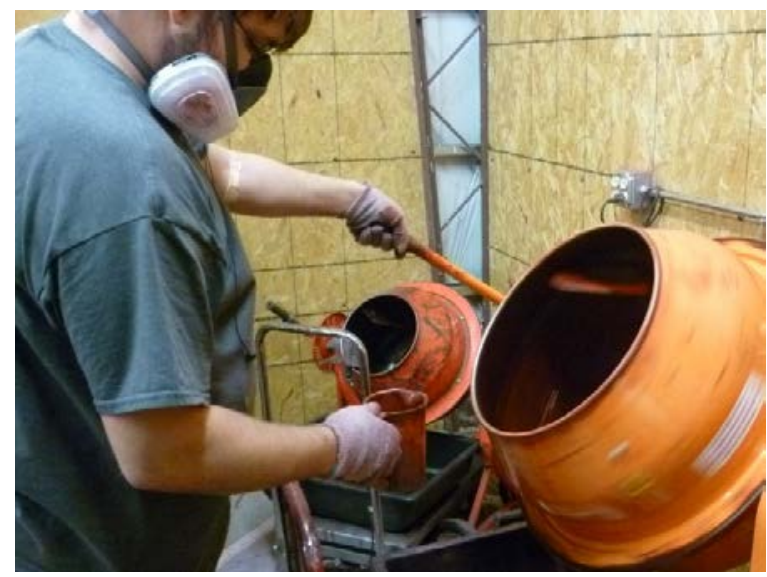

Figure 11. Employee manually pouring a mixture of powdered paint and solvent from a cup into a rotating tumbler containing uncoated bullets.

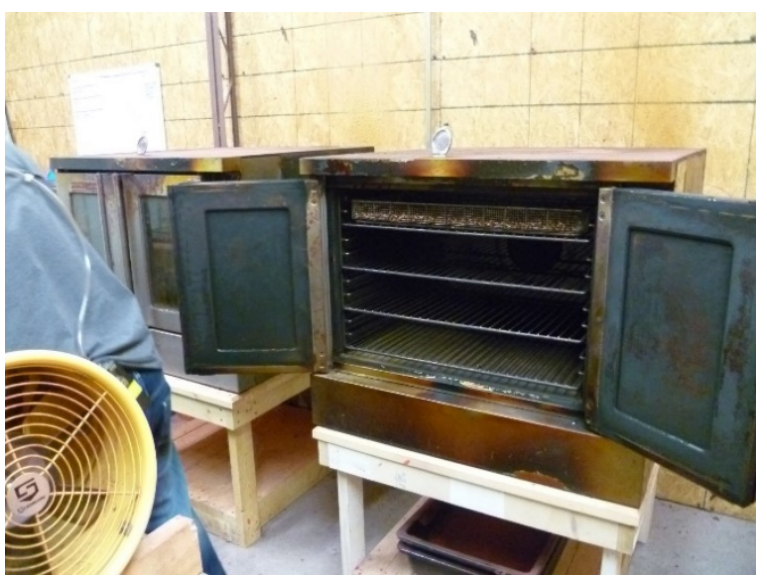

Figure 12. Trays of freshly coated bullets are placed into electrically-heated ovens to harden the paint coating. 


\section{Step 3: Packaging and Shipping}

- Employees moved containers of uncoated bullets, bullets with a wax coating, and coated bullets, to the packaging and shipping bay on the east side of the building.

- Packaging and shipping bay employees hand weighed and packaged containers of bullets, stacked them on pallets, and then used powered lifts to move pallets through the overhead door to the open-air shipping and receiving concrete dock along the north side of the building. 


\section{Section B: Methods, Results, and Discussion}

Our objectives were to:

- Evaluate the routes and extent of employees' lead exposures

- Determine the prevalence of elevated blood lead levels among employees

- Identify controls to protect employees from the hazards associated with lead exposure

We visited the company on October 23-24, 2017. On the first day, we observed workplace conditions and work processes and practices. We used this information to collect full-shift personal air samples for lead, antimony, and tin among nine production employees and one office employee on the second day. On this same day, we also took personal hand wipe samples for these metals among employees immediately before lunch and at the end of the work shift after employees had washed their hands. We looked at the airflow into the casting bay exhaust system using ventilation smoke tubes. We completed structured, confidential medical interviews on all employees, measured their venous blood lead levels (BLLs), and reviewed training materials and a past lead sampling report that the company had conducted.

Although not part of the original request, during our walk-through survey we noted that production areas were noisy and learned that some bullets received a baked-on coating. Evaluating noise and the bullet coating process were not a focus of this evaluation. For example, we were not prepared to conduct personal noise dosimetry or collect personal air samples for volatile organic compounds (VOCs) during the heating of the coated bullets. However, we did make spot (1-2 minute duration) measurements for noise and analyzed a bulk sample of the powdered paint used to coat the bullets. The bullet coating was done in a room that was separate from the other production bays.

\section{Methods: Health and Safety Program and Document Review}

We reviewed the company's employee handbook, which was last revised in October 2015, and a safety and health consultation report involving full-shift airborne lead sampling completed by the Missouri Department of Labor and Industrial Relations in 2012. We sent a list of company employees to the Missouri Adult Blood Lead Epidemiology and Surveillance (ABLES) program, and they crossreferenced their databases to identify past BLL results for these individuals. The company did not maintain OSHA Form 300 Log of Work-Related Injuries and Illnesses because they had fewer than 11 employees. No formal employee education and training program about the hazards of lead exposure, lead-related health effects, or lead exposure prevention was in place during our site visit in October 2017.

\section{Results: Health and Safety Program and Document Review}

The company did not have a written lead monitoring program and did not provide adequate employee training about the hazards and health effects of lead and ways to prevent or reduce exposure. The company's employee handbook described the personal protective equipment that all employees were required to use, including "gloves, hearing protection and eye protection." However, the required types 
of gloves or hearing or eye protection were not specified. The handbook also stated that employees "will be required to be tested for blood lead levels and hearing on a yearly basis or as directed" but did not state whether this testing would be provided at company or employee expense. In addition, this section stated that "tobacco use, eating, and drinking is prohibited in the manufacturing area" and "specified lead decontamination measures are to be used before the use of tobacco, eating, and drinking in approved areas and at end of shift."

The company owner reportedly advised employees to request annual BLL testing from their primary care provider, and employees were responsible for any testing costs. Several employees mentioned that they did not have a primary care provider. For those employees with past BLL testing results, there was no system in place to notify the employer of any elevated BLLs and the need to take corrective action.

In 2012, the Missouri Department of Labor and Industrial Relation's Missouri On-Site Safety and Health Consultation Program evaluated airborne lead levels at the company's previous location. Fullshift time-weighted average (TWA) lead exposures were below the OSHA permissible exposure limit (PEL) of $50 \mu \mathrm{g} / \mathrm{m}^{3}$.

According to Missouri ABLES records, four company employees, including two working in the office, one working in the packaging and shipping bay, and one working in the casting bay, had past BLL testing performed. Fifteen results were available for these four employees between the period of 20032017; all were $\geq 5 \mu \mathrm{g} / \mathrm{dL}$ (median: $13 \mu \mathrm{g} / \mathrm{dL}$; range: $6-33 \mu \mathrm{g} / \mathrm{dL}$ ). All BLL testing of Missouri residents is reportable to the Missouri Department of Health and Senior Services.

\section{Methods: Employee Health Assessment}

We invited all employees working during our site visit to participate in confidential medical interviews and blood lead testing. The interviews covered work history and practices, lead-related medical history, non-occupational sources of lead exposure, symptoms, and workplace safety and health concerns.

Venous blood samples were drawn by a NIOSH phlebotomist and analyzed by a standard atomic absorption spectroscopy method by the Missouri State Public Health Lab. A case of elevated BLL was defined as an employee of the company with a venous BLL $\geq 5$ micrograms per deciliter $(\mu \mathrm{g} / \mathrm{dL})$. This definition is consistent with the current case definitions used by the NIOSH ABLES program, the Council of State and Territorial Epidemiologists, and the Centers for Disease Control and Prevention (CDC) National Notifiable Diseases Surveillance System [CDC 2015, 2016; CSTE 2015].

\section{Results: Employee Health Assessment}

\section{Confidential Medical Interviews}

Ten employees and the owner of the company participated in confidential medical interviews. All 11 were white and non-Hispanic, and seven were male. Table C1 shows the tasks performed at work by interviewed employees. Two employees reported performing only office work. One employee reported participating in packaging, shipping, and office work, and another only performed packaging and shipping job tasks. These four employees reported spending little or no time in bullet production areas. 
Table C2 shows the frequency of personal protective equipment (PPE) use and hygiene practices at work that were reported by interviewed employees. Employees reported inconsistent handwashing practices during the work shift. Although the company informed us that shoe covers were available for use by employees during their work shift, no employees reported using them because they did not know they were available $(n=8)$, were concerned that shoe covers would increase the risk of falling $(n=2)$, and/or did not feel they were necessary $(n=2)$. Reported reasons for failing to change clothes and/or footwear before leaving work included feeling it was unnecessary $(n=5)$ or inconvenient $(n=4)$ and/or having no clothes or additional footwear to change into at work $(n=2)$.

Four employees smoked cigarettes and/or e-cigarettes during their work shifts. Among these four, the median number of cigarettes and/or e-cigarettes smoked daily was 15 (range: 2-20 cigarettes) with a median number of pack years smoked of 44 (range: 15-70.5 pack years). In addition, two reported always washing their hands, and two never washed their hands before smoking during a work shift. The two employees who reported never washing hands with lead removal soap worked in the office and did not feel that lead removal soap was necessary.

All 11 employees reported that they never showered before leaving work because they felt uncomfortable doing so $(\mathrm{n}=4)$, did not feel it was necessary $(\mathrm{n}=4)$, and/or felt it was inconvenient $(\mathrm{n}=3)$. Although the company informed us that it provided lead removal body wash, shampoo, and laundry detergent to employees, seven employees reported never using it. Reasons for failing to always use lead removal body wash, shampoo, and/or laundry detergent included not having any ( $\mathrm{n}=4$ ), feeling it was unnecessary $(n=5)$, and/or disliking the lead removal products the company provided $(\mathrm{n}=1)$.

Table C3 shows the cleaning activities interviewed employees reported. Two employees reported using a vacuum to clean. The company owner stated that the vacuum the employees used was equipped with a high-efficiency particulate air filter, although we did not confirm this. Of the nine employees who participated in cleaning activities, four reported wearing cotton on top of nitrile gloves, three reported wearing only nitrile gloves, and one reported only wearing cotton gloves. In addition, five of these employees reported wearing safety glasses while cleaning the facility.

We also asked about possible non-occupational sources of lead exposure. Eight employees reported having non-occupational lead exposures in the past 12 months including recreational shooting $(\mathrm{n}=7$ ), renovating or remodeling a home built before $1978(\mathrm{n}=5)$, making or reloading ammunition $(\mathrm{n}=3)$, and/or performing automobile body work or handling car batteries $(n=2)$.

\section{Blood Lead Level Testing}

Ten of 11 employees (all production employees plus one office employee) participated in BLL testing. All 10 employees had detectable BLLs (median: $8.5 \mu \mathrm{g} / \mathrm{dL}$; range: 4-35 $\mu \mathrm{g} / \mathrm{dL}$ ). Nine, including those working in the packaging and shipping bay, had BLLs that met our case definition of an elevated BLL of $\geq 5 \mu \mathrm{g} / \mathrm{dL}$. Three of these employees had worked at the company for less than 1 year. Four had 
BLLs that were above the current level of $\geq 10 \mu \mathrm{g} / \mathrm{dL}$ used by the Missouri Department of Health and Senior Services to determine which adults need further health department follow-up. No employees had a BLL at or above the OSHA medical removal level of $60 \mu \mathrm{g} / \mathrm{dL}$, but three had BLLs of 23-35 $\mu \mathrm{g} / \mathrm{dL}$. These levels are near or above the American Conference of Governmental Industrial Hygienists (ACGIH) recommended biological exposure limit for lead of $30 \mu \mathrm{g} / \mathrm{dL}$ [ACGIH 2017].

The three employees with the highest BLLs worked in the casting bay and coating room and reported regularly participating in cleaning activities, including dry sweeping. Additional reported work practices and conditions included periodically cutting lead ingots with a hand-held, gas-powered, water-cooled cutoff saw; regularly burned skin on the arms due to contact with molten lead; routinely changing the filters in the heating, ventilation, and air-conditioning system; inconsistent hand washing before eating and drinking; and inconsistent use of lead removal body wash, shampoo, and laundry detergent. All three of these employees reported always wearing safety glasses and both nitrile and cotton gloves throughout their shift, including during cleaning activities, and always using lead removal soap when washing their hands at work. All three also reported possible non-occupational lead exposures.

No employees reported a history of hypertension or chronic kidney disease. Table C4 shows possible lead-related symptoms experienced over the past 3 months by interviewed employees. Among the four employees with a BLL $>10 \mu \mathrm{g} / \mathrm{dL}$, two were asymptomatic while two reported a wide range of symptoms that included headache, dizziness, numbness, joint pain, fatigue, irritability, depression, and nightmares. One of the other five employees who reported possible lead-related symptoms refused BLL testing during our visit and the remaining four all had BLLs $<10 \mu \mathrm{g} / \mathrm{dL}$ (range: 5-9 $\mu \mathrm{g} / \mathrm{dL}$ ).

\section{Methods: Observations of Work Processes, Practices, and Conditions}

We evaluated the following in the casting, lubrisizing, and/or packaging and shipping bays, and/or the coating room:

- Workplace conditions and work processes and practices

- Local exhaust ventilation, general ventilation, and airflow direction

- Employee use of PPE

\section{Results: Observations of Work Processes, Practices, and Conditions}

- We saw food and drink stored in bullet production areas, but we did not see employees eating or drinking in these areas during this evaluation.

- Lead removal soap was available in the employee restroom, but the soap pump dispenser on the 1-gallon container was not working during the site visit. As a result, employees had to pour the soap from the 1-gallon container onto their hands. Abrasive (contains pumice) hand cleaner was also available in the employee restroom.

- We saw an employee in the bullet coating room wearing an elastomeric half-mask respirator equipped with combination organic vapor cartridges/N95 particulate pre-filters. The employee had facial hair that interfered with obtaining a proper facial seal with the respirator. When asked, 
the employee indicated that respirator use was required in this area. However, the company did not have a written respiratory protection program and had not provided the employee with respirator medical clearance, fit-testing, and training.

- Employees were not provided work uniforms or offered an employer-provided service for laundering work clothes. Employees wore their work clothes and shoes home at the end of a work shift and did not shower before leaving the plant. The company did provide employees with lead removal detergent for use at home.

- Employees were not required to wear safety shoes to protect their feet from injury. Several employees informed us that they had injured their feet in the past by dropping lead ingots on them while not wearing safety shoes.

- We saw a hand-held, gasoline-powered, water-cooled cutoff saw stored in the casting bay. We were informed that one employee periodically used the cutoff saw to cut larger lead ingots into smaller sizes that could then fit into the bullet casters. The employee who performed this task explained that the cutting was done on the cement pad outside of the casting bay. The employee reportedly wore a rain suit to keep his work clothes dry during cutting but did not use respiratory protection, although the employee mentioned that cutting the ingot generated dust.

- The overhead canopy hood exhaust ventilation system in the casting bay was not well designed. The primary shortcoming was the distance (several feet) that separated the bullet casters and the canopy hood. This design results in lead fume and fluxing smoke from the bullet casters not being efficiently captured by the canopy hood. The efficiency of this ventilation design can be improved by (1) physically decreasing the distance between the canopy hood and the bullet casters or (2) enclosing the bullet casters by using flexible strip curtains that are connected to the overhead canopy hood. The second option may be preferable because of likely lower installation costs as well as maintaining good access to the bullet casters.

- We observed floor drum and pedestal fans in the bullet casting bay and other bullet production areas during this evaluation but did not see them in use. Using fans can disrupt the effectiveness of the canopy hood exhaust ventilation system in the casting bay. However, disruption of the local exhaust ventilation system in the casting bay by these fans would be lessened once the bullet casters are enclosed by flexible strip curtains.

- General room air flowed from the shipping bay and into the lubrisizing bay and then into the casting bay before being exhausted to the outdoors (a preferable design).

\section{Methods: Exposure Assessment}

\section{Personal Air Sampling}

We collected full-shift personal air samples on 10 employees.

- We analyzed samples for lead, tin, and antimony using National Institute for Occupational Safety and Health (NIOSH) Method 7303. For the personal air sample collected on the bullet coating employee, we also analyzed for titanium, aluminum, and cobalt because these metals were present in the powdered paint used to coat bullets.

- We asked that employees leave their personal air sampler on during lunch unless they left the workplace. Most did not leave the workplace for lunch. 


\section{Hand and Surface Wipe Sampling}

We collected personal hand wipe samples for lead, tin, and antimony on employees immediately before lunch and at the end of the work shift (see Figures 13 and 14). Employees followed their usual clean-up procedures before this. We also collected surface wipe samples for these same metals in production and non-production areas.

- Before collecting a hand wipe sample, the NIOSH investigator put on a clean pair of nitrile gloves. The employees were then handed a clean pre-moistened GhostWipe ${ }^{\mathrm{TM}}$ and asked to wipe the front and back of their hands and between their fingers with this wipe for 1 minute. We asked them not to wipe past their wrists.

- After employees were finished wiping their hands, we had them place the used wipe in a clean, screw-top container for transport to the NIOSH lab.

- We used similar collection techniques for surface wipe sampling. We put on a clean pair of nitrile gloves and then used a clean premoistened GhostWipe ${ }^{\mathrm{TM}}$ to collect the surface wipe sample, following NIOSH Method 9100. We used a 100-square-centimeter disposable template to outline the surface area that we sampled.

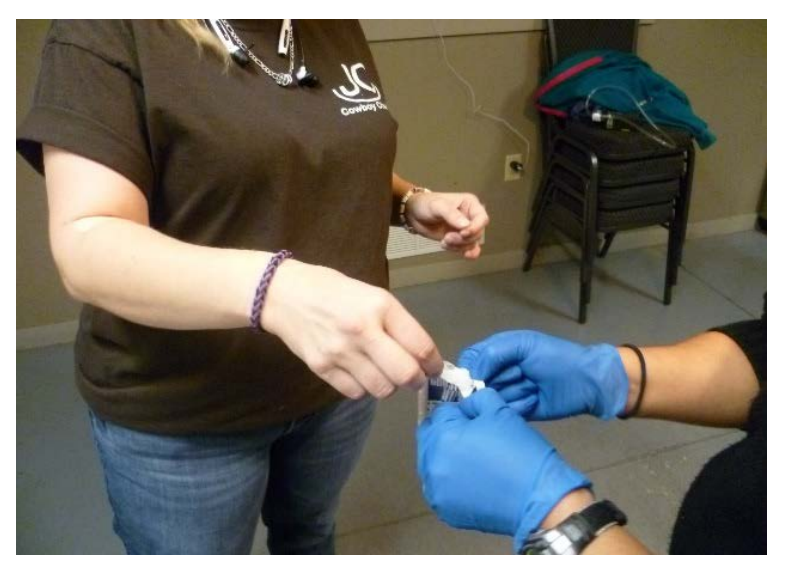

Figure 13. NIOSH investigator wearing nitrile gloves offers a new pre-moistened wipe to an employee.

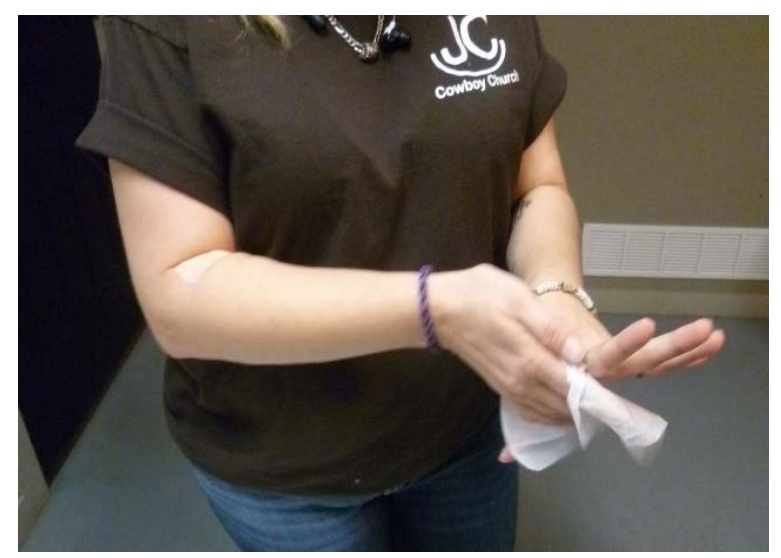

Figure 14. Employee wiping hands with a new pre-moistened wipe.

\section{Noise Measurements}

We measured noise levels in the production areas using a calibrated, battery-operated, type-2 sound level meter to estimate employees' personal noise exposures.

\section{Bulk Sample Analyses of the Bullet Coating Powder}

We analyzed a bulk sample of Hi-Tek-Lube Supercoat, a powdered paint from J\&M Specialized Products P/L, Upper Lansdowne, NSW (Australia) that the company used to coat bullets. We measured for 31 minerals and metals using NIOSH Method 7303.

Because the company heated the paint after it was applied to the bullets, we analyzed a bulk sample of the paint for VOCs. To replicate the conditions in the company's bullet coating room, we performed a heated headspace analysis of the powder following a modified Environmental Protection Agency (EPA) 
Method TO-15. One gram of the paint powder was heated to $500^{\circ} \mathrm{F}$ in a sample bottle, and a sample of the air within the bottle was analyzed by a gas chromatograph/mass spectrometer with the following instrument parameters.

Instrument conditions:

- Agilent 6890 gas chromatograph with a Phenomenex ZB-1ms 60 meter X 0.32 millimeter X 1.0 micrometer column

- Run time segments were $95^{\circ} \mathrm{F}$ for 5 minutes; $43^{\circ} \mathrm{F} /$ minute to $266^{\circ} \mathrm{F}$ hold for 0 minutes; and $68^{\circ} \mathrm{F} /$ minute to $500^{\circ} \mathrm{F}$ hold for 3 minutes. The total run time was 30.33 minutes.

- Agilent 5973 mass spectrometer run in full scan mode, 29 to 550 atomic mass units

- Electron multiplier voltage was set at tune values

\section{Results: Exposure Assessment}

\section{Personal Air Samples}

Employees' full-shift air sampling results for lead ranged from 2.3-20 micrograms per cubic meter $\left(\mu \mathrm{g} / \mathrm{m}^{3}\right)$. All were below the current OSHA, NIOSH, and ACGIH occupational exposure limit (OEL) of $50 \mu \mathrm{g} / \mathrm{m}^{3}$ (Table C5). The highest exposures were measured on casting bay employees. Not surprisingly, personal exposures to antimony and tin were much less than for lead, and well below applicable OELs, a finding that reflects the much lower content of these metals in the alloy used.

In addition to lead, antimony, and tin, we analyzed the personal air sample collected on the coating room employee for titanium, aluminum, and cobalt because these were the major metals present in the powdered paint used to coat bullets. Aluminum $\left(<2 \mu \mathrm{g} / \mathrm{m}^{3}\right)$ and cobalt $\left(<0.06 \mu \mathrm{g} / \mathrm{m}^{3}\right)$ were not detected. Titanium was detected but less than $0.090 \mu \mathrm{g} / \mathrm{m}^{3}$. These personal air sample results were well below applicable OELs.

\section{Hand and Surface Wipes}

Lead was detected on all hand wipe samples after washing (Table C6). Antimony and tin were detected, but in much lower amounts. The average amount of lead on employees' hands at lunch was 87 micrograms per wipe ( $\mu \mathrm{g} /$ wipe, range: 23-270); the average at the end of the shift was $121 \mu \mathrm{g} /$ wipe (range: 19-490). Neither NIOSH nor OSHA has OELs for lead on hands.

Lead was detected on all surfaces sampled (Table C7), along with much lower amounts of antimony and tin. Lead was present on surfaces in nonproduction areas, such as the table top and the microwave control panel in the employee break room. Lead was also detected on the office floor, but the level was about half the amount of lead found on a wipe sample taken from a nearby production floor. The highest surface lead result, and most unexpected, was from a wipe sample collected on an outdoor picnic table. The picnic table was neither near bullet production areas nor any exhaust ventilation fans. The OSHA lead standard requires that all surfaces be maintained as free as practicable of accumulations of lead [OSHA 1978]. 


\section{Noise}

We conducted short-term (1-5 minutes) spot noise measurements near employees working in the casting bay, lubrisizing bay, packaging and shipping bay, and the coating room. Noise levels in the packaging and shipping bay were low, less than 85 decibels A-weighted (dBA). Many employees in the plant wore audio headphones or earbuds, but none wore hearing protection.

- Casting bay. Eight of the 14 bullet casters were operating. This was a typical production rate.

o $92 \mathrm{dBA}$ midway between two bullet casters.

o $94 \mathrm{dBA}$ next to an employee working at a bullet caster.

- Lubrisizing bay. Two employees were using lubrisizing machines during these measurements.

o 85-87 dBA next to an employee lubrisizing "Cowboy 1" 250 grain, 45 caliber bullets.

o 87-89 dBA next to an employee lubrisizing “38 Match" 158 grain, 38 caliber bullets, the most popular bullet size produced by the company.

- Coating room.

o 95-99 dBA during a 5-minute task involving coating bullets using a tumbler. According to the coating room employee this task was done between 25 to 27 times per shift.

o $73 \mathrm{dBA}$ in coating room when no tumbling was performed.

Because noise was not a focus of the initial request, we were not prepared to collect personal, full-shift integrated noise measurements. Therefore, we do not know precisely what employees' full-shift noise exposures are. However, on the basis of short-term measurements the casting bay employees would likely exceed the NIOSH recommended exposure limit (REL) of $85 \mathrm{dbA}$ for an 8-hour time-weighted average. Noise levels for lubrisizing bay employees could also exceed the NIOSH REL of $85 \mathrm{dBA}$ if the work rate we observed was consistent throughout the workday. The bullet coating room employee likely exceeded the NIOSH REL of $85 \mathrm{dBA}$ and the OSHA action limit for noise, but would be below the OSHA PEL of $90 \mathrm{dBA}$. Performing the 5-minute task of tumbling bullets 27 times per work shift (total of 135 minutes) would result in a cumulative time-weighted average noise exposure of approximately 93.5 dBA using the NIOSH criterion, and $89.8 \mathrm{dBA}$ using the OSHA criterion. The company did not have a hearing conservation program, and hearing protection was neither required nor provided.

\section{Bulk Sample Analyses of the Bullet Coating Powder}

Table C8 summarizes the elements identified in the bulk sample of the powdered paint used to coat bullets for elements. The major metals in the powdered paint were titanium, cobalt, and aluminum.

Table C9 summarizes the VOCs identified from a headspace analysis of a bulk sample of the powdered paint. The VOC present in the highest estimated concentration was acetone, not unexpected considering that it was used in preparing a liquid suspension of the powdered paint. The other two VOCs present in highest estimated concentrations were 1-propanol (also called isopropyl alcohol) and 2-hydroxybenzaldehyde. The former is a commonly used disinfectant and solvent, while the latter is an aldehyde with a bitter almond odor that likely accounted for the odor that was readily detected when the freshly coated bullets were heated to $400^{\circ} \mathrm{F}$. There are no OELs for 2-hydroxybenzaldehyde. 


\section{Discussion: Lead}

Nine of 10 employees had elevated BLLs. Not surprisingly, the highest BLLs were found among casting bay employees responsible for melting lead ingots to cast bullets. In addition, the overhead local exhaust ventilation system in the casting bay was not effectively capturing airborne emissions from the bullet casters. However, packaging and shipping bay employees also had elevated BLLs. This area was furthest from the casting bay, and the primary task of boxing loose bullets was one that we assumed would generate less airborne lead than in the casting bay. As shown in Table C5 this assumption was correct, as airborne lead levels in casting bay employees ranged from 12 to $20 \mu \mathrm{g} / \mathrm{m}^{3}$, compared to less than $4 \mu \mathrm{g} / \mathrm{m}^{3}$ in packaging and shipping bay employees. Although dry sweeping and wiping of lead contaminated surfaces instead of vacuuming, and cutting lead ingots with a saw were practices that could contribute to airborne lead exposures, no employee that we sampled had a personal air exposure above current OELs.

These results suggest that while airborne lead exposures may contribute to elevated BLLs, other work practices and routes of exposure likely contributed as well. Many of the work practices were further exacerbated by the company's lack of an effective lead monitoring and control program. For example, all 11 employees that we tested had detectable lead on their hands after their usual clean-up procedures, both before lunch and before going home. Inconsistent glove use; failing to wash hands with lead removal soap before eating, drinking, or smoking; and keeping food and drink in bullet production areas are practices that can result in lead ingestion. Using an abrasive de-greasing soap instead of or before using a lead removal soap may remove the outer layer of skin and could also result in increased dermal lead absorption. Burns such as the ones we observed on some casting bay employees can also compromise the skin barrier and increase dermal lead absorption. Another factor that can affect employees' lead exposures at work as well as take-home exposure to household members was the lack of an employer-provided laundry service [CDC 2009, 2012]. Additionally, not providing work uniforms, shoes (or shoe covers), and not requiring employees to shower before leaving the facility increases the risk of lead exposure to employees and household members.

In our evaluation, two employees with BLLs $>10 \mu \mathrm{g} / \mathrm{dL}$ and five employees with BLLs between $5 \mu \mathrm{g} / \mathrm{dL}$ and $10 \mu \mathrm{g} / \mathrm{dL}$, reported multiple nonspecific symptoms including fatigue, irritability, depression, and difficulty concentrating over the past 3 months. We did not identify any employees with the most severe health effects (e.g., anemia, severe neurologic effects, etc.) that can result from BLLs $\geq$ $40 \mu \mathrm{g} / \mathrm{dL}$, or health effects such as fertility problems, mild increases in blood pressure, and subtle neurocognitive changes that may develop in individuals with lower BLLs [ACGIH 2017; NTP 2012]. In 2012, the National Toxicology Program (NTP) concluded that the evidence supporting an association between psychiatric symptoms and BLLs $<10 \mu \mathrm{g} / \mathrm{dL}$ is limited. Associating an individual's specific symptoms with BLLs in this range is challenging, especially in light of our small sample size. In this evaluation, individual BLL results were communicated to all employees, and those with elevated BLLs were advised to discuss their results and any symptoms they may have with a medical provider. 


\section{Discussion: Other}

Employees in the casting bay and coating room were likely exposed to noise levels that exceeded the NIOSH REL, and employees in the lubrisizing bay may be overexposed. None of the employees in these areas wore hearing protection, although many wore audio headphones or ear buds with the mistaken belief that these devices offered some hearing protection.

The coating room employee was not overexposed to airborne lead, antimony, tin, aluminum, titanium, or cobalt during this evaluation. However, this employee was unnecessarily exposed to VOCs released when the freshly coated bullets were heated in ovens to harden the paint. Exposures to VOCs can be reduced by providing local exhaust ventilation at the workbench used to store the powdered paint and solvents and to mix the paint and solvent together. In addition, the ovens used to harden the coated bullets can be enclosed so that emissions can be vented to outside the building. A ventilation engineer can provide options for ventilating the workbench and enclosing the ovens.

\section{Limitations}

Our evaluation had some limitations. First, industrial hygiene sampling can only document exposures on the days of sampling in the locations sampled. These results may not be representative of conditions during other days. Second, we did not perform clinical examinations to diagnose any lead-related medical conditions, although we did use standardized questions to assess for lead-related symptoms during our structured medical interviews. Third, the small size and homogenous nature of the population sampled limit the statistical power and generalizability of our evaluation results. 


\section{Section C: Tables}

Table C1. Description of work tasks reported by interviewed employees

\begin{tabular}{lc}
\hline Task & Number of employees $(\mathrm{N}=11)$ \\
\hline Cutting lead ingots with hand-held cutoff saw & 1 \\
Casting & 5 \\
Lubrisizing & 5 \\
Coating & 4 \\
Packaging and shipping & 4 \\
Office work & 4 \\
\hline
\end{tabular}

${ }^{*}$ An infrequently performed task that was not performed during this evaluation.

Table C2. Frequency of PPE use and hygiene practices by interviewed employees $(\mathrm{N}=11)$

\begin{tabular}{lcccc}
\hline & \multicolumn{4}{c}{ Frequency } \\
\hline Practice & Always & Often & Sometimes & Never \\
\hline Wear gloves & 7 & 1 & 2 & 1 \\
Wear eye protection & 8 & 1 & 1 & 1 \\
Wear shoe covers* & $\mathbf{0}$ & $\mathbf{0}$ & $\mathbf{0}$ & $\mathbf{1 1}$ \\
Wash hands before eating/drinking & 6 & 4 & 1 & 0 \\
Wash hands with lead removal soap & 8 & 1 & 0 & 2 \\
Change clothes before leaving work & $\mathbf{0}$ & $\mathbf{0}$ & $\mathbf{0}$ & $\mathbf{1 1}$ \\
Change footwear before leaving work & $\mathbf{0}$ & $\mathbf{0}$ & $\mathbf{0}$ & $\mathbf{1 1}$ \\
Wash hands before leaving work & 7 & 2 & 0 & 2 \\
Shower before leaving work & $\mathbf{0}$ & $\mathbf{0}$ & $\mathbf{0}$ & $\mathbf{1 1}$ \\
Shower with lead removal body wash/shampoo & 2 & 0 & 3 & 6 \\
Wash clothes with lead removal detergent & 2 & 1 & 1 & 7 \\
\hline
\end{tabular}

*Practices shown in bold are those that employees never do. 
Table C3. Description of cleaning activities reported by interviewed employees

\begin{tabular}{lc}
\hline Activity & Number of employees $(\mathrm{N}=9)$ \\
\hline Collect lead bullet scraps for reuse or disposal & 9 \\
Dry sweep production floors & 8 \\
Empty waste from lead bullet production machines & 6 \\
Clean production surfaces with a dry cloth & 5 \\
Vacuum facility & 2 \\
\hline
\end{tabular}

Table C4. Symptoms that could be consistent with lead exposure reported over the last 3 months by interviewed employees

\begin{tabular}{lc}
\hline Symptom & Number of employees $(\mathrm{N}=11)$ \\
\hline Any symptom & 7 \\
Decreased libido & 7 \\
Numbness or tingling of hands or feet & 5 \\
Difficulty concentrating & 3 \\
Irritability & 3 \\
Nightmares & 3 \\
Severe fatigue & 3 \\
Depressed mood & 2 \\
Dizziness & 2 \\
Joint pain & 2 \\
Severe headache or migraine & 1 \\
\hline
\end{tabular}


Table C5. Personal air sample results for lead, antimony, and tin

\begin{tabular}{|c|c|c|c|c|}
\hline Job & $\begin{array}{l}\text { Sampling time } \\
\text { (minutes) }\end{array}$ & $\begin{array}{l}\text { Lead } \\
\left(\mu \mathrm{g} / \mathrm{m}^{3}\right)\end{array}$ & $\begin{array}{l}\text { Antimony } \\
\left(\mu \mathrm{g} / \mathrm{m}^{3}\right)\end{array}$ & $\begin{array}{c}\operatorname{Tin}_{\left(\mu \mathrm{g} / \mathrm{m}^{3}\right)} \\
\end{array}$ \\
\hline Casting & 466 & 20 & {$[1.2]^{*}$} & 0.90 \\
\hline Casting & 453 & 12 & {$[0.62]$} & [0.39] \\
\hline Lubrisizing supervisor & 461 & 4.6 & ND† & [0.31] \\
\hline Lubrisizing and casting $\ddagger$ & 372 & 4.2 & ND & ND \\
\hline Operations manager§ & 461 & 4.3 & {$[0.34]$} & ND \\
\hline Coating & 428 & 12 & [0.62] & {$[0.42]$} \\
\hline Packaging and shipping & 450 & 2.8 & {$[0.37]$} & ND \\
\hline Packaging and shipping & 447 & 3.8 & [0.39] & {$[0.45]$} \\
\hline Office manager $\ddagger$ & 325 & 4.3 & ND & ND \\
\hline Logistics associate $\mathbb{T}$ & 457 & 2.3 & ND & {$[0.30]$} \\
\hline \multicolumn{2}{|c|}{ Minimum detectable concentration (for an 870 liter air sample) } & - & 0.3 & 0.2 \\
\hline \multicolumn{2}{|c|}{ Minimum quantifiable concentration (for an 870 liter air sample) } & - & 1.3 & 0.67 \\
\hline \multicolumn{2}{|c|}{ NIOSH REL, OSHA PEL, ACGIH TLV } & 50 & 500 & 2,000 \\
\hline
\end{tabular}

*Values in brackets are estimates because they are between the minimum detectable concentration and minimum quantifiable concentration.

†Not detected, below the minimum detectable concentration.

łEmployee left for part of the work day, resulting in less than an 8-hour sample being collected.

§Employee could work throughout the plant, as needed.

TEmployee worked in packaging, shipping, and lubrisizing, as needed. 
Table C6. Employee hand wipe results* in micrograms of metal per wipe

\begin{tabular}{|c|c|c|c|c|c|c|}
\hline \multirow[t]{2}{*}{ Job } & \multicolumn{3}{|c|}{$\begin{array}{c}\text { Before lunch } \\
\text { hand wipe results }\end{array}$} & \multicolumn{3}{|c|}{$\begin{array}{c}\text { End of shift } \\
\text { hand wipe results }\end{array}$} \\
\hline & Lead & Antimony & Tin & Lead & Antimony & Tin \\
\hline Casting & 91 & 6.2 & 9.6 & 300 & 14 & 8.3 \\
\hline Casting & 120 & 8.5 & 7.0 & 490 & 27 & 20 \\
\hline Lubrisizing supervisor & 110 & 7.6 & 5.3 & 75 & 5.3 & 3.1 \\
\hline Lubrisizing and casting & 110 & 6.8 & 11 & 30 & 2.4 & {$[1.7] \dagger$} \\
\hline Operations manager & 48 & 3.2 & 7.4 & 36 & [1.7] & {$[1.4]$} \\
\hline Coating & 270 & 15 & 9.1 & 160 & 7 & 4.9 \\
\hline Packaging and shipping & 24 & 1.9 & 2.4 & 22 & [1.6] & 7.9 \\
\hline Packaging and shipping & 23 & {$[1.5]$} & 2.7 & 23 & [1.6] & 4.8 \\
\hline Office manager & 15 & {$[1.6]$} & 5.7 & 19 & [1.7] & 6 \\
\hline Logistics associate & 110 & 5.5 & 4 & 140 & 6.5 & 4.1 \\
\hline Owner & 32 & 2.1 & 3.6 & 34 & 2.5 & 8.7 \\
\hline Limit of detection & 0.3 & 0.5 & 0.7 & 0.3 & 0.5 & 0.7 \\
\hline Limit of quantitation & 1.0 & 1.8 & 2.2 & 1.0 & 1.8 & 2.2 \\
\hline
\end{tabular}

${ }^{\star}$ Results are blank corrected.

†Values shown in brackets are estimates because they are between the limit of detection and limit of quantification. More uncertainty is associated with these results.

Table C7. Surface wipe results* in micrograms of metal per wipe $\dagger$

\begin{tabular}{lccc}
\hline Location & Lead & Antimony & Tin \\
\hline Microwave control panel & 4.2 & ND & {$[0.89] \S$} \\
Table top, break room & 30 & {$[1.8]$} & 5.3 \\
Break room floor, near door & 1,100 & 54 & 23 \\
Desk top, office & 12 & {$[0.99]$} & 8.5 \\
Laminate floor in office & 580 & 31 & 11 \\
Concrete floor in shipping area, near office & 930 & 34 & 17 \\
Outdoor picnic table & 10,000 & 650 & 200 \\
\hline Limit of detection & 0.3 & 0.5 & 0.7 \\
Limit of quantitation & 1.0 & 1.8 & 2.2 \\
\hline
\end{tabular}

${ }^{*}$ Results are blank corrected.

†Surface area sampled for each location was 100 square centimeters.

$\ddagger$ Not detected, less than the limit of detection of 0.5 micrograms per sample.

$\S$ Values shown in brackets are estimates because they are between the limit of detection and limit of quantification. More uncertainty is associated with these results. 
Table C8. Results from elemental analysis of a powder paint bulk sample

\begin{tabular}{|c|c|c|}
\hline Analyte & Results, mg/kg* & Comments \\
\hline Aluminum & 760 & \\
\hline Antimony & ND† & Limit of detection $=2$ \\
\hline Arsenic & 14 & \\
\hline Barium & 1.3 & \\
\hline Beryllium & ND & Limit of detection $=0.09$ \\
\hline Cadmium & {$[0.62] \ddagger$} & \\
\hline Calcium & 43 & \\
\hline Chromium & 14 & \\
\hline Cobalt & 3,900 & \\
\hline Copper & ND & Limit of detection $=0.2$ \\
\hline Iron & 230 & \\
\hline Lanthanum & 0.66 & \\
\hline Lead & ND & Limit of detection $=0.9$ \\
\hline Lithium & 3,000 & \\
\hline Magnesium & 110 & \\
\hline Manganese & 2.7 & \\
\hline Molybdenum & 0.48 & \\
\hline Nickel & 4.5 & \\
\hline Phosphorus & 73 & \\
\hline Potassium & 390 & \\
\hline Selenium & ND & Limit of detection $=7$ \\
\hline Silver & ND & Limit of detection $=0.9$ \\
\hline Strontium & 0.37 & \\
\hline Tellurium & 32 & \\
\hline Thallium & ND & Limit of detection $=4$ \\
\hline Tin & ND & Limit of detection $=0.9$ \\
\hline Titanium & 17,000 & \\
\hline Vanadium & ND & Limit of detection $=0.7$ \\
\hline Yttrium & ND & Limit of detection $=0.04$ \\
\hline Zinc & 6.3 & \\
\hline Zirconium & 5.0 & \\
\hline
\end{tabular}

*1 milligram per kilogram is equivalent to 1 part per million.

†Not detected (less than limit of detection).

‡Result shown in brackets was between the limit of detection of 0.2 milligrams per kilogram and 0.70 milligrams per kilogram for cadmium. 
Table C9. Results from a heated headspace analysis of a powdered paint bulk sample

\begin{tabular}{|c|c|c|c|}
\hline Tentatively identified compounds & $\begin{array}{l}\text { Retention time } \\
\text { (minutes) }\end{array}$ & $\begin{array}{c}\text { CAS* } \\
\text { number }\end{array}$ & $\begin{array}{c}\text { Estimated } \\
\text { amount }(\mathrm{ng} / \mathrm{g}) \dagger\end{array}$ \\
\hline Acetaldehyde & 4.489 & $75-07-0$ & 65 \\
\hline Methanol & 4.662 & $67-56-1$ & 205 \\
\hline Methanamine, N,N-dimethyl- & 5.066 & $75-50-3$ & 73 \\
\hline Ethanol & 5.528 & $64-17-5$ & 94 \\
\hline Acetone $\neq$ & 5.851 & $67-64-1$ & 2,967 \\
\hline 2-Propanol‡ & 6.082 & $67-63-0$ & 721 \\
\hline Methyl acetate & 6.936 & $79-20-9$ & 72 \\
\hline Carbon disulfide & 7.144 & $75-15-0$ & 34 \\
\hline Acetic acid, ethyl ester & 9.534 & $141-78-6$ & 307 \\
\hline 1-Butanol & 11.358 & $71-36-3$ & 29 \\
\hline Benzene & 11.462 & $71-43-2$ & 651 \\
\hline Pentanal & 12.385 & $110-62-3$ & 11 \\
\hline 2-Pentanone, 4-methyl- & 14.152 & $108-10-1$ & 46 \\
\hline Benzene, methyl & 15.537 & $108-88-3$ & 321 \\
\hline 2-Hexanone & 15.941 & $591-78-6$ & 10 \\
\hline 3-Penten-2-one, 4-methyl- & 16.299 & $141-79-7$ & 34 \\
\hline Acetic acid, butyl ester & 16.934 & $123-86-4$ & 24 \\
\hline Cyclopentanone, 3-methyl- & 17.858 & $1757-42-2$ & 12 \\
\hline 1-Methoxy-2-propyl ester of acetic acid & 18.631 & $108-65-6$ & 287 \\
\hline 1-Hexanol & 18.885 & $111-27-3$ & 13 \\
\hline Benzene, ethyl- & 18.989 & $100-41-4$ & 207 \\
\hline m\&p-Xylene & 19.266 & 179601-23-1 & 219 \\
\hline 2-Heptanone & 19.52 & $110-43-0$ & 12 \\
\hline Styrene and C8 hydrocarbon & 19.89 & NAS & 19 \\
\hline o-Xylene & 20.074 & $95-47-6$ & 154 \\
\hline Benzaldehyde & 21.679 & $100-52-7$ & 10 \\
\hline 2-Heptanone, 5-methyl- & 21.887 & $18217-12-4$ & 13 \\
\hline 3-cyclohexene-1-carbonitrile & 22.868 & $100-45-8$ & 29 \\
\hline 1-Hexanol, 2-ethyl- & 23.411 & $104-76-7$ & 75 \\
\hline Benzaldehyde, 2-hydroxy- & 23.665 & $90-02-8$ & 1,124 \\
\hline C10 hydrocarbon & 24.346 & NA & 13 \\
\hline Benzenamine, N,N-dimethyl- & 24.577 & $121-69-7$ & 31 \\
\hline Benzofuran, 2-methyl and C11 hydrocarbon & 24.946 & NA & 14 \\
\hline C11 hydrocarbon & 25.166 & NA & 19 \\
\hline C11 hydrocarbon & 25.373 & NA & 11 \\
\hline C11 hydrocarbon & 25.466 & NA & 11 \\
\hline Cyclopentasiloxane, decamethyl- & 25.604 & NA & 59 \\
\hline 1-Dodecene & 26.043 & $541-02-6$ & 15 \\
\hline Dodecane & 26.17 & $112-41-4$ & 161 \\
\hline C12 cyclic hydrocarbon & 26.436 & $112-40-3$ & 18 \\
\hline C12 hydrocarbon & 26.724 & NA & 35 \\
\hline C12 hydrocarbon & 26.805 & NA & 13 \\
\hline C13 hydrocarbon & 27.904 & NA & 17 \\
\hline C13 cyclic hydrocarbon & 27.325 & NA & 30 \\
\hline C13 cyclic hydrocarbon & 27.405 & NA & 16 \\
\hline C13 alkene & 27.486 & NA & 11 \\
\hline C13 hydrocarbon & 27.578 & NA & 17 \\
\hline C13 hydrocarbon & 27.625 & NA & 12 \\
\hline
\end{tabular}

${ }^{\star}$ Chemical abstract number.

†Nanograms per gram is equivalent to parts per billion.

$\ddagger$ According to the lab, the gas chromatograph peaks for acetone and 2-propanol were saturated so the estimated amounts shown should be considered low.

$\S$ Not applicable 


\section{Section D: Occupational Exposure Limits}

NIOSH investigators refer to mandatory (legally enforceable) and recommended OELs for chemical, physical, and biological agents when evaluating workplace hazards. OELs have been developed by federal agencies and safety and health organizations to prevent adverse health effects from workplace exposures. Generally, OELs suggest levels of exposure that most employees may be exposed to for up to 10 hours per day, 40 hours per week, for a working lifetime, without experiencing adverse health effects. However, not all employees will be protected if their exposures are maintained below these levels. Some may have adverse health effects because of individual susceptibility, a pre-existing medical condition, or a hypersensitivity (allergy). In addition, some hazardous substances act in combination with other exposures, with the general environment, or with medications or personal habits of the employee to produce adverse health effects. Most OELs address airborne exposures, but some substances can be absorbed directly through the skin and mucous membranes.

Most OELs are expressed as a TWA exposure. A TWA refers to the average exposure during a normal 8- to 10-hour workday. Some chemical substances and physical agents have recommended short-term exposure limits or ceiling limits. Unless otherwise noted, the short term exposure limit is a 15-minute TWA exposure. It should not be exceeded at any time during a workday. The ceiling limit should not be exceeded at any time.

In the United States, OELs have been established by federal agencies, professional organizations, state and local governments, and other entities. Some OELs are legally enforceable limits; others are recommendations.

- The U.S. Department of Labor OSHA permissible exposure limits (29 CFR 1910 [general industry]; 29 CFR 1926 [construction industry]; and 29 CFR 1917 [maritime industry]) are legal limits. These limits are enforceable in workplaces covered under the Occupational Safety and Health Act of 1970.

- NIOSH RELs are recommendations based on a critical review of the scientific and technical information and the adequacy of methods to identify and control the hazard. NIOSH RELs are published in the NIOSH Pocket Guide to Chemical Hazards [NIOSH 2010]. NIOSH also recommends risk management practices (e.g., engineering controls, safe work practices, employee education/training, PPE, and exposure and medical monitoring) to minimize the risk of exposure and adverse health effects.

- Another set of OELs commonly used and cited in the United States is the ACGIH TLVs. The TLVs are developed by committee members of this professional organization from a review of the published, peer-reviewed literature. TLVs are not consensus standards. They are considered voluntary exposure guidelines for use by industrial hygienists and others trained in this discipline "to assist in the control of health hazards" [ACGIH 2017]. 
Outside the United States, OELs have been established by various agencies and organizations and include legal and recommended limits. The Institut für Arbeitsschutz der Deutschen Gesetzlichen Unfallversicherung (Institute for Occupational Safety and Health of the German Social Accident Insurance) maintains a database of international OELs from European Union member states, Canada (Québec), Japan, Switzerland, and the United States. The database, available at http://www.dguv.de/ifa/GESTIS/GESTIS-Internationale-Grenzwerte-für-chemische-Substanzenlimit-values-for-chemical-agents/index-2.jsp, contains international limits for more than 2,000 hazardous substances and is updated periodically.

OSHA requires an employer to furnish employees a place of employment free from recognized hazards that cause or are likely to cause death or serious physical harm [Occupational Safety and Health Act of 1970 (Public Law 91-596, sec. 5(a)(1))]. This is true in the absence of a specific OEL. It also is important to keep in mind that OELs may not reflect current health-based information.

When multiple OELs exist for a substance or agent, NIOSH investigators generally encourage employers to use the lowest OEL when making risk assessment and risk management decisions.

\section{Lead}

Inorganic lead is a naturally occurring, soft metal that has been mined and used in industry since ancient times. It comes in many forms (e.g., lead acetate, lead chloride, lead chromate, lead nitrate, lead oxide, lead phosphate, and lead sulfate). Lead is considered toxic to all organ systems and serves no useful purpose in the body.

Occupational exposure to inorganic lead occurs via inhalation of lead-containing dust and fume and ingestion of lead particles from contact with lead-contaminated surfaces. Exposure may also occur through transfer of lead to the mouth from contaminated hands or cigarettes when careful attention to hygiene, particularly hand washing, is not practiced. In addition to the inhalation and ingestion routes of exposure, lead can be absorbed through the skin, particularly through damaged skin [Filon et al. 2006; Stauber et al. 1994; Sun et al. 2002].

\section{Occupational Exposure Limits for Lead in Air}

In the United States, employers in general industry are required by law to follow the OSHA lead standard [29 CFR 1910.1025]. This standard was established in 1978 and has not yet been updated to reflect the current scientific knowledge regarding the health effects of lead exposure. Under the OSHA standard the PEL for airborne exposure to lead is $50 \mu \mathrm{g} / \mathrm{m}^{3}$ of air for an 8-hour TWA, with an action level of $30 \mu \mathrm{g} / \mathrm{m}^{3}$ (also an 8-hour TWA). In 2013, the California Department of Public Health recommended that California OSHA lower the PEL for lead to 0.5 to $2.1 \mu \mathrm{g} / \mathrm{m}^{3}$ (8-hour TWA) [Billingsley 2013].

Other guidelines for lead exposure, which are not legally enforceable, are often followed in the United States. Like the OSHA lead standard, these guidelines have also not been updated. The NIOSH REL and ACGIH TLV for lead are $50 \mu \mathrm{g} / \mathrm{m}^{3}$ as an 8-hour work shift [ACGIH 2017; NIOSH 2010]. 


\section{Surface Exposure Limits for Lead}

Neither NIOSH nor OSHA has established surface contamination limits for lead in the workplace. The U.S. Environmental Protection Agency and the U.S. Department of Housing and Urban Development limit lead on surfaces in public buildings and child-occupied housing to less than 40 micrograms of lead per square foot [EPA 1998; HUD 2012]. OSHA requires in its substance-specific standard for lead that all surfaces be maintained as free as practicable of accumulations of lead [29 CFR 1910.1025(h)(1)]. An employer with workplace lead exposures must have regular and effective cleaning of surfaces in areas such as change areas, storage facilities, and lunchroom/eating areas to ensure they are as free as practicable from lead contamination.

\section{Blood Lead Levels}

In most cases, an individual's BLL is a good indication of recent exposure to lead because the half-life of lead (the time interval it takes for the quantity in the body to be reduced by half its initial value) is $1-$ 2 months [Centers for Disease Control and Prevention 2013; Lauwerys and Hoet 2001; Moline and Landrigan 2005]. Most lead in the body is stored in the bones, with a half-life of years to decades. Measuring bone lead, however, is primarily done only for research. Elevated zinc protoporphyrin levels have also been used as an indicator of chronic lead intoxication. However, other factors, such as iron deficiency, can cause an elevated zinc protoporphyrin level, so monitoring the BLL over time is more specific for evaluating chronic occupational lead exposure.

The OSHA lead standard mandates medical removal for an employee with a single BLL of $\geq 60 \mu \mathrm{g} / \mathrm{dL}$, or three BLLs averaging $\geq 50 \mu \mathrm{g} / \mathrm{dL}$, and permits return to work once the employee's BLL decreases to $<40 \mu \mathrm{g} / \mathrm{dL}$ [29 CFR 1910.1025]. ACGIH recommends that employee BLLs be controlled to below 20 $\mu \mathrm{g} / \mathrm{dL}$, and also designates lead as an animal carcinogen [ACGIH 2017]. CDC recommends removal of pregnant women from lead-exposed work areas when BLLs are $\geq 10 \mu \mathrm{g} / \mathrm{dL}$ [Centers for Disease Control and Prevention 2010]. In 2013, the California Department of Public Health recommended that California OSHA keep BLLs below the range of 5 to $10 \mu \mathrm{g} / \mathrm{dL}$ [Billingsley 2013]. In 2015, NIOSH designated $5 \mu \mathrm{g} / \mathrm{dL}$ of whole blood, in a venous blood sample, as the reference BLL for adults [Centers for Disease Control and Prevention 2015].

\section{Health Effects of Lead}

The OSHA PEL, NIOSH REL, and ACGIH TLV may prevent overt symptoms of lead poisoning, but they do not protect workers from lead's contributions to conditions such as hypertension, renal dysfunction, or reproductive and cognitive effects [Brown-Williams et al. 2009; Holland and Cawthorn 2016; Institute of Medicine 2012; Schwartz and Hu 2007; Schwartz and Stewart 2007]. Generally, acute lead poisoning with symptoms has been documented in persons having BLLs above $70 \mu \mathrm{g} / \mathrm{dL}$. These BLLs are rare today in the United States, largely as a result of workplace controls put in place to comply with current OELs. When present, acute lead poisoning can cause a myriad of adverse health effects including abdominal pain, hemolytic anemia, and neuropathy. Lead poisoning has, in very rare cases, progressed to encephalopathy and coma [Moline and Landrigan 2005].

People with chronic lead poisoning, which is more likely at current OELs, may not have symptoms or they may have nonspecific symptoms that may not be recognized as being associated with lead 
exposure. These symptoms include headache, joint and muscle aches, weakness, fatigue, irritability, depression, constipation, anorexia, and abdominal discomfort [Moline and Landrigan 2005].

The NTP released a monograph on the health effects of low-level lead exposure [NTP 2012]. For adults, the NTP concluded the following about the evidence regarding health effects of lead (Table D1).

Table D1. Evidence regarding health effects of lead in adults

\begin{tabular}{|c|c|c|c|}
\hline Health area & $\begin{array}{c}\text { NTP } \\
\text { conclusion }\end{array}$ & Principal health effects & $\begin{array}{l}\text { Blood lead } \\
\text { evidence }\end{array}$ \\
\hline \multirow[t]{3}{*}{ Neurological } & Sufficient & Increased incidence of essential tremor & Yes, $<10 \mu \mathrm{g} / \mathrm{dL}$ \\
\hline & Limited & $\begin{array}{l}\text { Psychiatric effects, decreased hearing, } \\
\text { decreased cognitive function, increased } \\
\text { incidence of amyotrophic lateral sclerosis }\end{array}$ & Yes, $<10 \mu \mathrm{g} / \mathrm{dL}$ \\
\hline & Limited & Increased incidence of essential tremor & Yes, $<5 \mu \mathrm{g} / \mathrm{dL}$ \\
\hline Immune & Inadequate & & Unclear \\
\hline \multirow[t]{2}{*}{ Cardiovascular } & Sufficient & $\begin{array}{l}\text { Increased blood pressure and } \\
\text { increased risk of hypertension }\end{array}$ & Yes, $<10 \mu \mathrm{g} / \mathrm{dL}$ \\
\hline & Limited & $\begin{array}{l}\text { Increased cardiovascular-related mortality } \\
\text { and electrocardiography abnormalities }\end{array}$ & Yes, $<10 \mu \mathrm{g} / \mathrm{dL}$ \\
\hline Renal & Sufficient & Decreased glomerular filtration rate & Yes, $<5 \mu \mathrm{g} / \mathrm{dL}$ \\
\hline \multirow[t]{6}{*}{ Reproductive } & Sufficient & Women: reduced fetal growth & Yes, $<5 \mu \mathrm{g} / \mathrm{dL}$ \\
\hline & Sufficient & $\begin{array}{l}\text { Men: adverse changes in sperm parameters } \\
\text { and increased time to pregnancy }\end{array}$ & Yes, $\geq 15-20 \mu \mathrm{g} / \mathrm{dL}$ \\
\hline & Limited & $\begin{array}{c}\text { Women: increase in spontaneous abortion } \\
\text { and preterm birth }\end{array}$ & Yes, $<10 \mu \mathrm{g} / \mathrm{dL}$ \\
\hline & Limited & Men: decreased fertility & Yes, $\geq 10 \mu \mathrm{g} / \mathrm{dL}$ \\
\hline & Limited & Men: spontaneous abortion & Yes, $\geq 31 \mu \mathrm{g} / \mathrm{dL}$ \\
\hline & Inadequate & $\begin{array}{l}\text { Women and Men: stillbirth, } \\
\text { endocrine effects, birth defects }\end{array}$ & Unclear \\
\hline
\end{tabular}

Various organizations have assessed the relationship between lead exposure and cancer. According to the Agency for Toxic Substances and Disease Registry [ATSDR 2007] and the NTP [NTP 2011], inorganic lead compounds are reasonably anticipated to cause cancer in humans. The International Agency for Research on Cancer classifies inorganic lead as probably carcinogenic to humans [WHO 2006]. According to the American Cancer Society [ACS 2011], some studies show a relationship between lead exposure and lung cancer, but these results might be affected by exposure to cigarette smoking and arsenic. Some studies show a relationship between lead and stomach cancer, and these findings are less likely to be affected by the other exposures. The results of studies looking at other cancers, including brain, kidney, bladder, colon, and rectum, are mixed.

\section{Medical Surveillance and Management}

To prevent acute and chronic health effects, a panel of experts convened by the Association of Occupational and Environmental Clinics published guidelines for the management of adult lead exposure [Kosnett et al. 2007]. The panel recommended BLL testing for all lead-exposed employees, regardless of the airborne lead concentration. These recommendations do not apply to pregnant 
women, who should avoid BLLs $>5 \mu \mathrm{g} / \mathrm{dL}$. Removal from lead exposure should be considered if control measures over an extended period do not decrease BLLs to $<10 \mu \mathrm{g} / \mathrm{dL}$ or an employee has a medical condition that would increase the risk of adverse health effects from lead exposure.

NIOSH also supports the health-based medical surveillance and management recommendations summarized in Table D2. This table includes recommendations from an expert panel [Kosnett et al. 2007] and those from the California Department of Public Health, American College of Occupational and Environmental Medicine, and the Council of State and Territorial Epidemiologists to prevent acute and chronic health effects [ACOEM 2010; CDPH 2009, 2014; CSTE 2009, 2013; Holland and Cawthorn 2016].

Table D2. Health-based medical surveillance recommendations for lead-exposed employees

\begin{tabular}{|c|c|}
\hline Category of exposure & Recommendations \\
\hline All lead exposed workers & $\begin{array}{l}\text { - Baseline or preplacement medical history and physical } \\
\text { examination, baseline BLL, and serum creatinine }\end{array}$ \\
\hline $\mathrm{BLL}<5 \mu \mathrm{g} / \mathrm{dL}$ & $\begin{array}{l}\text { BLL monthly for first } 3 \text { months placement, or upon change in } \\
\text { task to higher exposure, then BLL every } 6 \text { months; if BLL } \\
\text { increases } \geq 5 \mu \mathrm{g} / \mathrm{dL} \text {, evaluate exposure and protective measures, } \\
\text { and increase monitoring if indicated }\end{array}$ \\
\hline BLL 5-9 $\mu \mathrm{g} / \mathrm{dL}$ & $\begin{array}{l}\text { - Discuss health risks } \\
\text { - Minimize exposure } \\
\text { - Consider removal for pregnancy and certain medical conditions } \\
\text { BLL monthly for first } 3 \text { months placement or every } 2 \text { months for } \\
\text { the first } 6 \text { months placement, or upon change in task to higher } \\
\text { exposure, then BLL every } 6 \text { months; if BLL increases } \geq 5 \mu \mathrm{g} / \mathrm{dL} \text {, } \\
\text { evaluate exposure and protective measures, and increase } \\
\text { monitoring if indicated }\end{array}$ \\
\hline BLL 10-19 $\mu \mathrm{g} / \mathrm{dL}$ & $\begin{array}{l}\text { - Discuss health risks } \\
\text { - } \text { Decrease exposure } \\
\text { - Remove from exposure for pregnancy } \\
\text { - } \text { Consider removal for certain medical conditions or BLL } \geq 10 \mu \mathrm{g} / \mathrm{dL} \\
\text { for extended period } \\
\text { - } \quad \text { BLL every } 3 \text { months; evaluate exposure, engineering controls, and } \\
\text { work practices; consider removal. } \\
\text { - Revert to BLL every } 6 \text { months after } 3 \mathrm{BLLs}<10 \mu \mathrm{g} / \mathrm{dL}\end{array}$ \\
\hline BLL $20-29 \mu \mathrm{g} / \mathrm{dL}$ & $\begin{array}{l}\text { - Remove from exposure for pregnancy } \\
\text { - Remove from exposure if repeat BLL measured in } 4 \text { weeks } \\
\text { remains } \geq 20 \mu \mathrm{g} / \mathrm{dL} \\
\text { - } \text { Annual lead medical exam recommended } \\
\text { - } \text { Monthly BLL testing } \\
\text { - Consider return to work after } 2 \mathrm{BLLs}<15 \mu \mathrm{g} / \mathrm{dL} \text { a month apart, } \\
\text { then monitor as above }\end{array}$ \\
\hline BLL 30-49 $\mu \mathrm{g} / \mathrm{dL}$ & $\begin{array}{l}\text { - Remove from exposure } \\
\text { - } \text { Prompt medical evaluation } \\
\text { - } \text { Monthly BLL testing } \\
\text { - } \text { Consider return to work after } 2 \mathrm{BLLs}<15 \mu \mathrm{g} / \mathrm{dL} \text { a month apart, } \\
\text { then monitor as above }\end{array}$ \\
\hline
\end{tabular}




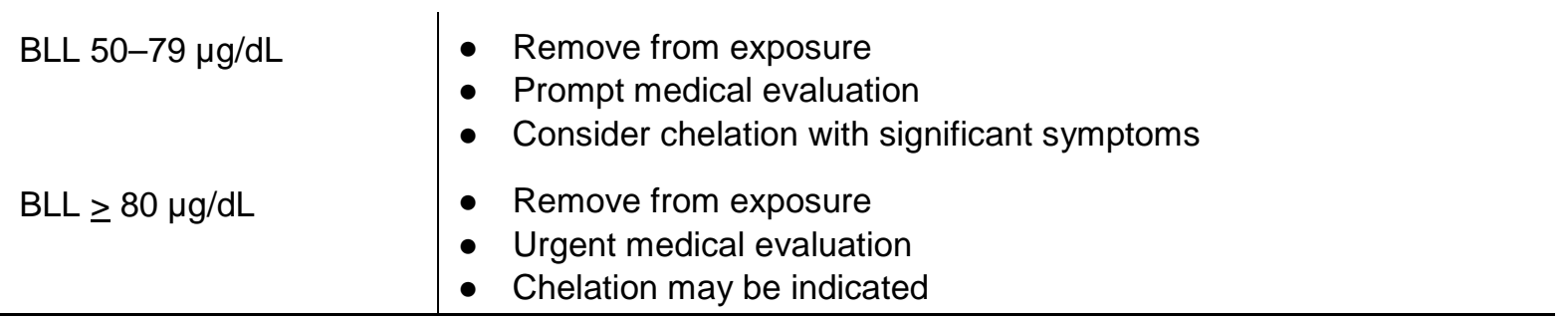

Adapted from Kosnett et al. 2007, CSTE 2013, and CDPH 2014

\section{Take-home Contamination}

Occupational exposures to lead can result in exposures to household members, including children, from take-home contamination. Take-home contamination occurs when lead dust is transferred from the workplace on employees' skin, clothing, shoes, and other personal items to their vehicle and home [Centers for Disease Control and Prevention 2009, 2012]. CDC considers a BLL in children of $5 \mu \mathrm{g} / \mathrm{dL}$ or higher as a reference level above which public health actions should be initiated and states that no safe BLL in children has been identified [CDC 2013].

The U.S. Congress passed the Workers' Family Protection Act in 1992 (29 U.S.C. 671a). The Act required NIOSH to study take-home contamination from workplace chemicals and substances, including lead. NIOSH found that take-home exposure is a widespread problem [NIOSH 1995]. Workplace measures effective in preventing take-home exposures were (1) reducing exposure in the workplace, (2) changing clothes before going home and leaving soiled clothing at work for laundering, (3) storing street clothes in areas separate from work clothes, (4) showering before leaving work, and (5) prohibiting removal of toxic substances or contaminated items from the workplace. NIOSH noted that preventing take-home exposure is critical because decontaminating homes and vehicles is not always effective. Normal house cleaning and laundry methods are inadequate, and decontamination can expose the people doing the cleaning and laundry.

\section{Noise}

Noise-induced hearing loss is an irreversible condition that progresses with noise exposure. More than 22 million U.S. workers are estimated to be exposed to workplace noise levels above $85 \mathrm{dBA}$ [Tak et al. 2009]. The preferred unit for reporting noise measurements is the dBA. "A-weighting" is used because it provides a better estimate of hearing loss risk than other measurements [Earshen 2003]. NIOSH estimates that employees exposed to an average daily noise level of $85 \mathrm{dBA}$ over a 40 -year working lifetime have an $8 \%$ excess risk of material hearing impairment.

The NIOSH REL for noise is $85 \mathrm{dBA}$ as an 8-hour TWA. For calculating exposure limits, NIOSH uses a 3-decibel exchange rate. Using the NIOSH criterion, an employee can be exposed to $88 \mathrm{dBA}$ for no more than 4 hours, $91 \mathrm{dBA}$ for 2 hours, $94 \mathrm{dBA}$ for 1 hour, $97 \mathrm{dBA}$ for 0.5 hours, etc. Exposure to impulsive noise should never exceed $140 \mathrm{dBA}$. The NIOSH REL can also be adjusted for extended work shifts. NIOSH recommends employees use hearing protection and participate in a hearing conservation program when noise exposures exceed the REL [NIOSH 1998]. 
The OSHA PEL is $90 \mathrm{dBA}$ and their action level is $85 \mathrm{dBA}$; both are 8-hour TWAs. Unlike NIOSH, OSHA uses a less conservative $5-\mathrm{dB}$ exchange rate. Using the OSHA criterion, an employee may be exposed to noise levels of $95 \mathrm{dBA}$ for no more than 4 hours, $100 \mathrm{dBA}$ for 2 hours, $105 \mathrm{dBA}$ for 1 hour, $110 \mathrm{dBA}$ for 0.5 hours, etc. Exposure to impulsive or impact noise must not exceed 140 decibel peak noise level. OSHA does not adjust their PEL for extended work shifts, but does adjust their action level. OSHA requires a hearing conservation program when noise exposures exceed the action level [OSHA 1971].

Employees exposed to noise should have baseline and yearly hearing tests to evaluate their hearing thresholds and determine whether their hearing has changed over time. In workplace hearing conservation programs, hearing thresholds must be measured at 500 hertz $(\mathrm{Hz}), 1,000 \mathrm{~Hz}, 2,000 \mathrm{~Hz}$, 3,000 Hz, 4,000 Hz, and 6,000 Hz. Additionally, NIOSH recommends testing at 8,000 Hz [NIOSH 1998]. The OSHA noise standard requires that hearing tests be analyzed to determine if an employee's ability to hear is declining, a concept called standard threshold shift. NIOSH and OSHA define standard threshold shift differently [NIOSH 1998; OSHA 1971]. 


\section{Section E: References}

\section{Lead}

ACGIH [2017]. 2017 TLVs ${ }^{\circledR}$ and BEIs ${ }^{\circledR}$ : threshold limit values for chemical substances and physical agents and biological exposure indices. Cincinnati, OH: American Conference of Governmental Industrial Hygienists.

ACOEM [2010]. ACOEM provides input to OSHA on key issues facing agency in 2010. Letter to David Michaels. Elk Grove Village, IL: American College of Occupational and Environmental Medicine, http:/ / www.acoem.org/Page2Column.aspx?PageID=7392\&id=6676.

ACS [2011]. Lead. Atlanta, GA: American Cancer Society, http://www.cancer.org/cancer/cancercauses/othercarcinogens/athome/lead.

ATSDR [2007]. Toxicological profile for lead. Atlanta, GA: U.S. Department of Health and Human Services.

Billingsley KJ [2013]. Letter of September 30, 2013, from K.J. Billingsley, California Department of Public Health, to Juliann Sum, Division of Occupational Safety and Health (Cal/OSHA), California Department of Industrial Relations.

Brown-Williams H, Lichterman J, Kosnett M [2009]. Indecent exposure: lead puts workers and families at risk. Health Research for Action, University of California, Berkeley. Perspectives 4(1):1-9, http://www.healthresearchforaction.org/sites/default/files/PDF PERSPECTIVES IndecentExp $\% 20$ FNL 0.pdf.

CDC [2009]. Childhood lead poisoning associated with lead dust contamination of family vehicles and child safety seats - Maine, 2008. MMWR 58(32):890-893.

CDC [2010]. Guidelines for the identification and management of lead exposure in pregnant and lactating women, November 2010, https://www.cdc.gov/nceh/lead/publications/leadandpregnancy2010.pdf.

CDC [2012]. Take-home lead exposure among children with relatives employed at a battery recycling facility - Puerto Rico, 2011. MMWR 61(47):967-970.

CDC [2013]. Blood lead levels in children aged 1-5 years — United States, 1999-2010. MMWR 62(13):245-248.

CDC [2015]. Adult blood lead epidemiology and surveillance (ABLES), http://www.cdc.gov/niosh/topics/ables/description.html. 
CDC [2016]. National Notifiable Diseases Surveillance System (NNDSS), Lead, Elevated Blood Levels 2016 Case Definition, https://wwwn.cdc.gov/nndss/conditions/lead-elevated-blood-levels/casedefinition $/ 2016 /$.

CDPH [2009]. Medical guidelines for the lead-exposed worker. Sacramento, CA: California Department of Public Health, Occupational Lead Poisoning Prevention Program, http://www.cdph.ca.gov/programs/olppp/Documents/medgdln.pdf.

CDPH [2014]. Management guidelines for blood lead levels in adults. Sacramento, CA: California Department of Public Health, Occupational Lead Poisoning Prevention Program, http://www.cdph.ca.gov/programs/olppp/documents/adultmgtguide.pdf.

CFR. Code of Federal Regulations. Washington, DC: U.S. Government Printing Office, Office of the Federal Register.

CSTE [2009]. Public health reporting and national notification for elevated blood lead levels. CSTE position statement 09-OH-02. Atlanta, GA: Council of State and Territorial Epidemiologists, http://c.ymcdn.com/sites/www.cste.org/resource/resmgr/PS/09-OH-02.pdf.

CSTE [2013]. Management guidelines for blood lead levels in adults. Atlanta, GA: Council of State and Territorial Epidemiologists, http://c.ymcdn.com/sites/www.cste.org/resource/resmgr/OccupationalHealth/ManagementGuidelin esforAdult.pdf.

CSTE [2015]. Public health reporting and national notification for elevated blood lead levels. CSTE position statement 15-EH-01. Atlanta, GA: Council of State and Territorial Epidemiologists, http://c.ymcdn.com/sites/www.cste.org/resource/resmgr/2015PS/2015PSFinal/15-EH-01.pdf.

EPA [1998]. Risk analysis to support standards for lead in paint, dust, and soil. Environmental Protection Agency Publication EPA-747-R097-006. Washington, DC, http://www2.epa.gov/lead/riskanalysis-support-standards-lead-paint-dust-and-soil-volume-ichapters-1-7-and-appendix-epa.

Filon FL, Boeniger M, Maina G, Adami G, Spinelli P, Damian A [2006]. Skin absorption of inorganic lead $(\mathrm{PbO})$ and the effect of skin cleansers. J Occup Environ Med 48(7):692-699, https://doi.org/10.1097/01.jom.0000214474.61563.1c.

Holland MG, Cawthorn D [2016]. ACOEM position statement: workplace lead exposure. JOEM 58(12):371-373, https://doi.org/10.1097/jom.0000000000000928.

HUD [2012]. Guidelines for the evaluation and control of lead-based paint hazards in housing, http://portal.hud.gov/hudportal/HUD? src=/program offices/healthy homes/lbp/hudguidelines. 
Institute of Medicine [2012]. Potential health risks from recurrent lead exposure of DOD firing range personnel. Washington, DC: National Academies Press, https://www.ncbi.nlm.nih.gov/books/NBK206966/pdf/Bookshelf NBK206966.pdf.

Kosnett MJ, Wedeen RP, Rothenberg SJ, Hipkins KL, Materna BL, Schwartz BS, Hu H, Woolf A [2007]. Recommendations for medical management of adult blood lead exposure. Environ Health Perspect 115(3):463-471, https://doi.org/10.1289/ehp.9784.

Lauwerys RR, Hoet P [2001]. Industrial chemical exposure: guidelines for biological monitoring. 3rd ed. Boca Raton, FL: CRC Press, LLC, pp. 21-180.

Moline JM, Landrigan PJ [2005]. Lead. In: Rosenstock L, Cullen MR, Brodkin CA, Redlich CA, eds. Textbook of clinical occupational and environmental medicine. 2nd ed. Philadelphia, PA: Elsevier Saunders, pp. 967-979.

NIOSH [1995]. Report to Congress on the workers' home contamination study conducted under the Workers' Family Protection Act 29 U.S.C. 671a. Cincinnati, OH: U.S. Department of Health and Human Services, Centers for Disease Control and Prevention, National Institute for Occupational Safety and Health, DHHS (NIOSH) Publication No. 95-123, http://www.cdc.gov/niosh/docs/95123/.

NIOSH [2010]. NIOSH pocket guide to chemical hazards. Cincinnati, OH: U.S. Department of Health and Human Services, Centers for Disease Control and Prevention, National Institute for Occupational Safety and Health, DHHS (NIOSH) Publication No. 2010-168c, http://www.cdc.gov/niosh/npg/.

NTP [2011]. Report on carcinogens, 12th ed. Research Triangle Park, NC: U.S. Department of Health and Human Services, National Institutes of Health, National Institute of Environmental Health Sciences, National Toxicology Program, http://ntp.niehs.nih.gov/ntp/roc/twelfth/profiles/Lead.pdf.

NTP [2012]. Monograph on the health effects of low-level lead. Research Triangle Park, NC: U.S. Department of Health and Human Services, National Institutes of Health, National Institute of Environmental Health Sciences, National Toxicology Program, https://ntp.niehs.nih.gov/ntp/ohat/lead/final/monographhealtheffectslowlevellead newissn 508.pdf.

Schwartz BS, Hu H [2007]. Adult lead exposure: time for change. Environ Health Perspect 115(3):451454, https://doi.org/10.1289/ehp.9782.

Schwartz BS, Stewart WF [2007]. Lead and cognitive function in adults: a question and answers approach to a review of the evidence for cause, treatment, and prevention. Int Rev Psychiatry 19(6):671-692, https://dx.doi.org/10.1080/09540260701797936. 
Stauber JL, Florence TM, Gulson B, Dale L [1994]. Percutaneous absorption of inorganic lead compounds. Sci Total Environ 145(1-2):55-70, https://dx.doi.org/10.1016/0048-9697(94)90297-6.

Sun CC, Wong TT, Hwang YH, Chao KY, Jee SH, Wang JD [2002]. Percutaneous absorption of inorganic lead compounds. Am Ind Hyg Assoc J 63(5):641-646, https://dx.doi.org/10.1080/15428110208984751.

WHO [2006]. IARC monographs on the evaluation of carcinogenic risks to humans volume 87. Inorganic and organic lead compounds. Summary of data reported and evaluation. World Health Organization, Geneva, Switzerland, http://monographs.iarc.fr/ENG/Monographs/vol87/.

\section{Noise}

Earshen J [2003]. Sound measurement: instrumentation and noise descriptors. In: Berger EH, Royster LH, Royster JD, Driscoll DP, Layne M, eds. The noise manual. 5th rev. ed. Fairfax, VA: American Industrial Hygiene Association.

NIOSH [1998]. Criteria for a recommended standard: occupational noise exposure (revised criteria 1998). Cincinnati, OH: U.S. Department of Health and Human Services, Centers for Disease Control and Prevention, National Institute for Occupational Safety and Health, DHHS (NIOSH) Publication No. 98-126, http://www.cdc.gov/niosh/docs/98-126/pdfs/98-126.pdf.

Tak S, Davis RR, Calvert GM [2009]. Exposure to hazardous workplace noise and use of hearing protection devices among U.S. workers-NHANES, 1999-2004. Am J Ind Med 52(5):358-371, http://dx.doi.org/10.1002/ajim.20690. 


\section{Delivering on the Nation's promise: Promoting produc tive workplaces through safety and health research}

To receive NIOSH documents or more information about occupational safety and health topics, please contact NIOSH:

Telephone: 1-800-CDC-INFO (1-800-232-4636)

TTY: 1-888-232-6348

CDC INFO: www.cdc.gov/info

orvisit the NIOSH Web site at www.cdc.gov/niosh

For a monthly update on news at $\mathrm{NIOSH}$, subscribe to $\mathrm{NIOSH}$ eNews by visiting www.cdc.gov/niosh/eNews. 